\title{
Failure to Down-Regulate miR-154 Expression in Early Postnatal Mouse Lung Epithelium Suppresses Alveologenesis, with Changes in Tgf- $\beta$ Signaling Similar to those Induced by Exposure to Hyperoxia
}

\author{
Cho-Ming Chao 1,2,3,+, Gianni Carraro ${ }^{4,+}$, Zvonimir A. Rako ${ }^{2}$, Johannes Kolck ${ }^{2}$, \\ Jamschid Sedighi $^{2}$, Volker Zimmermann ${ }^{2}$, Alena Moiseenko ${ }^{2}$, Jochen Wilhelm ${ }^{2} \mathbb{D}$, \\ Brittany M. Young ${ }^{5}$, Lei Chong ${ }^{6}$, Jin $\mathrm{Wu}^{7}$, Adriana Contreras ${ }^{8}$, Parviz Minoo ${ }^{9}$, \\ Guillermo Barreto ${ }^{8,10}$ (D), David Warburton ${ }^{11, *}$ and Saverio Bellusci ${ }^{1,2, *(D)}$
}

1 Key laboratory of Interventional Pulmonology of Zhejiang Province, Department of Pulmonary and Critical Care Medicine, First Affiliated Hospital of Wenzhou Medical University, Wenzhou 325027, Zhejiang, China; Cho-Ming.Chao@paediat.med.uni-giessen.de

2 Cardio-Pulmonary Institute and Institute for Lung Health, Universities of Giessen and Marburg Lung Center, Member of the German Center for Lung Research, Justus-Liebig-University Giessen, 35392 Giessen, Germany; Zvone91@web.de (Z.A.R.); johannes.kolck@charite.de (J.K.); jamschid.sedighi@gmail.com (J.S.); volkerzimmermann92@gmail.com (V.Z.); alena.v.moiseenko@gmail.com (A.M.); jochen.wilhelm@chemie.bio.uni-giessen.de (J.W.)

3 Division of General Pediatrics and Neonatology, University Children's Hospital Gießen, Justus-Liebig-University, 35392 Giessen, Germany

4 Cedars-Sinai Medical Center, Lung and Regenerative Medicine Institutes, Department of Medicine, Los Angeles, CA, 90027, USA; Gianni.Carraro@csmc.edu

5 Department of Neurology, University of California, Los Angeles, CA 90095, USA; brittanym.young@gmail.com

6 Institute of Pediatrics, Discipline of Pediatric Respiratory Medicine, Second Affiliated Hospital of Wenzhou Medical University, Wenzhou 325027, Zhejiang, China; chongpeilei@gmail.com

7 College of Life and Environmental Sciences, Wenzhou University, Wenzhou 325027, Zhejiang, China; cugin1519@163.com

8 Lung Cancer Epigenetics, Member of the German Center of Lung Research (Deutsches Zentrum für Lungenforschung, DZL), Max-Planck-Institute for Heart and Lung Research, 61231 Bad Nauheim, Germany; madecontreras@gmail.com (A.C.); Guillermo.Barreto@mpi-bn.mpg.de (G.B.)

9 Department of Pediatrics, Division of Newborn Medicine, University of Southern California, Children's Hospital Los Angeles, Los Angeles, CA 90027, USA; minoo@usc.edu

10 Brain and Lung Epigenetics (BLUE), Glycobiology, Cell Growth and Tissue Repair Research Unit (Gly-CRRET), Université Paris-Est Créteil (UPEC), 94010 Créteil, France

11 Developmental Biology and Regenerative Medicine Program, Saban Research Institute of Children's Hospital Los Angeles and University of Southern California, Los Angeles, CA 90027, USA

* Correspondence: Saverio.Bellusci@innere.med.uni-giessen.de; (S.B.); dwarburton@chla.usc.edu (D.W.); Tel.: +49-641-9946730 (S.B.)

+ These authors contributed equally to this work.

Received: 21 January 2020; Accepted: 13 March 2020; Published: 2 April 2020

\begin{abstract}
Background: Bronchopulmonary dysplasia (BPD) is a lung disease of preterm born infants, characterized by alveolar simplification. MicroRNA $(m i R)$ are known to be involved in many biological and pathological processes in the lung. Although a changed expression has been described for several miR in BPD, a causal role remains to be established. Results: Our results showed that the expression level of miR-154 increases during lung development and decreases postnatally. Further, hyperoxia treatment maintains high levels of miR-154 in alveolar type 2 cells (AT2). We hypothesized that the decrease in miR-154 expression in AT2 cells is required for normal alveologenesis. To test this hypothesis, we generated a novel transgenic mouse allowing doxycycline-based miR-154
\end{abstract}


overexpression. Maintenance of miR-154 expression in the postnatal distal lung epithelium under normoxia conditions is sufficient to reproduce the hypoalveologenesis phenotype triggered by hyperoxia. Using a pull-down assay, we identified Caveolin 1 as a key downstream target of miR-154. Caveolin1 protein is downregulated in response to overexpression of $m i R-154$. This is associated with increased phosphorylation of Smad3 and Tgf- 1 signaling. We found that AT2 cells overexpressing miR-154 display decreased expression of AT2 markers and increased expression of AT1 markers. Conclusion: Our results suggest that down-regulation of $m i R-154$ in postnatal lung may function as an important physiological switch that permits the induction of the correct alveolar developmental program, while conversely, failure to down-regulate miR-154 suppresses alveolarization, leading to the common clinically observed phenotype of alveolar simplification.

Keywords: miR-154; AT2; hyperoxia; Caveolin1; Tgf-11; alveolar simplification

\section{Introduction}

Alveologenesis is an essential developmental phase occurring postnatally in mice and during late gestation in humans. This phase is characterized by elastin deposition in the alveolar sacs leading to the formation of "secondary septa" at the very same place of elastin deposition. The cells which are responsible for the depositing ring shaped elastin structures that surround the mouths of developing alveoli are called "alveolar myofibroblasts". The "secondary septa" form the spheroidal walls of mature alveoli. As the process of alveolarization progresses, it leads to a marked increase of the alveolar surface and therefore the area available for gas exchange increases. The process of alveologenesis mainly takes part in the period of P0-P14 in mice (approximately equivalent to the first 6 months after birth in humans). Afterwards, from P14 through P28, the maturation of the alveoli occurs [1]. Many different signaling ligands and receptors are involved in the process of alveolarization: absence of Platelet derived growth factor alpha (Pdgf $\alpha$ ) leads to lack of Pdgf receptor $\alpha$ expressing cells, which potentially form a progenitor population for the $\alpha$-smooth muscle actin-expressing alveolar myofibroblasts [2-4]. Sonic hedgehog (Shh) signaling is also required for proper alveolar myofibroblast differentiation [1]. In addition, in a newborn murine hypoalveologenesis model, Perl et al. showed that the re-alveolarization induced by application of retinoic acid is dependent on Fgf signaling [4]. Interestingly, the absence of both Fgfr3 and Fgfr4 leads to impaired alveologenesis [5] but the endogenous Fgf ligands for these receptors are still unclear. During mouse lung development, increased Fgf signaling in the mesenchyme leads to impaired alveolar myofibroblast formation, associated with decreased elastin deposition [6].

Bronchopulmonary dysplasia (BPD) is the most common chronic airway disease of prematurely born infants, whereby low gestational age and weight at birth embody important factors increasing the probability of BPD occurrence (e.g., $20 \%$ of the infants born with a gestational weight of under $1500 \mathrm{~g}$ and a gestational age of under 30 weeks develop BPD in the US) [7-10]. Between 10,000 and 15,000 preterm infants are affected by BPD each year in the US alone [11]. The number of BPD patients increases due to improved therapy and increased survival rate at lower gestational ages $[7,9,12]$. From the pathophysiological point of view, BPD prevents alveologenesis from occurring. Oxygen toxicity associated with mechanical ventilation is considered as one of the major injurious factor in the pathogenesis of BPD. BPD interferes with the process of alveolarization, leading to a phenotype of alveolar simplification, which has been quantified as a decreased number but with an increased diameter of alveoli in rats [13]. Furthermore, thicker alveolar walls remain and the development of the pulmonary vasculature is disrupted [8], collectively leading to restricted gas exchange due to reduced alveolar surface and increased distance within the alveolar wall for gas diffusion between the alveolar lumen and the capillary lumen.

As more patients with BPD survive due to optimized therapy $[9,14]$, but nevertheless carry symptoms and have impaired lung function, there is an urgent need for a better understanding of 
the pathophysiological mechanisms underlying this complex disease. In addition, the development of new and better diagnostic approaches (e.g., miRNAs as markers in peripheral blood [8]) that can potentially distinguish between prematurely born infants at risk of developing BPD will enable therapy at an early stage or prevent unnecessary therapy. Finally, new therapeutic tools will be instrumental to attenuate the symptoms of impaired lung function after surviving BPD to improve the condition of these patients and to lower the high costs of caring for infants with this disease.

MicroRNAs ( $m i R s$ ) are small regulatory RNAs in mammals that account for approximately $1 \%$ of the genome. They are 22- to 25-nucleotide-long single-stranded RNAs processed from hairpin transcripts, that regulate gene expression post transcriptionally in eukaryotes by binding at the $3^{\prime}$-UTR regions of the target mRNA, thus leading to mRNA cleavage, degradation or translational repression. The maturation of hairpin transcripts give rise to two isoforms, a $3 p$ guide strand and $5 p$ sister passenger strand. In general, only one isoform remains while the complementary isoform is degraded. But in some cases both isoforms can be produced thereby allowing the silencing of specific sets of genes through base pairing to a minimal recognition sequence [15]. miRs are involved in almost every known molecular process [16]. Yet, only little is known about their role in late lung development nor their involvement in BPD [8]. Although a changed expression has been described for several miRs in BPD, a causal role in BPD remains to be established [8,13].

miRs in general are now known to be involved in many biological and pathological processes in the lung [17]. miR-154-3p and miR-154-5p (initially called miR-154 and miR-154* are both part of the human "DLK1-DIO3 genomic region", which is located on chromosome region 14q32 (murine chromosome 12F2 region) [18-21]. Among the paternally expressed imprinted genes in this genomic region, DLK1, RTL1, and DIO3 and the maternally expressed imprinted genes MEG3 (Gtl2), MEG8 (Rian), and an anti-sense RTL1 (asRTL1) are found. In addition, this region contains a miR cluster with 54 miRs, thus being one of the largest $m i R$ containing clusters in humans [18]. The miRs from this cluster are only expressed from the maternally inherited chromosome [20]. Furthermore none of these miRs binds their target $m R N A s$ with full complementarity, suggesting that they may act on their targets by translational repression rather than by post-transcriptional decay [20]. The expression of the genes on the maternal chromosome $12 \mathrm{~F}$ in mice is regulated by so-called "DMRs" (differentially methylated regions) [22,23]. Various members of this cluster play roles in human pathologies [18].

miR-154-3p and miR-154-5p are highly conserved between mice and humans, which has been demonstrated by sequence equality [24] (hsa-miR-154-3p $=m m u-m i R-154-3 p=5^{\prime}$-AAU CAU ACA CGG UUG ACC UAU U-3'; $h s a-m i R-154-5 p=$ mmu-miR-154-5p = 5' - UAG GUU AUC CGU GUU GCC UUC G). Within the DLK1-DIO3 genomic region, this sequence is located in the maternally expressed imprinted intergenic region Mirg [19,20], which is regulated by an intergenic germline-derived differentially methylated region [19].

Similar expression profiles of these miRs in embryonic and adult lung tissue were found in humans and mice, indicating evolutionary conservation of these miRs as well as their potential functions in lung development across the two species [19].

In this study, we demonstrate that the expression level of miR-154, which increases during the fetal phases of fetal lung development, normally decreases postnatally. We further demonstrate that hyperoxia treatment maintains high levels of $m i R-154$ in alveolar type 2 cells (AT2). We therefore hypothesized that the postnatal decrease in miR-154 expression in AT2 cells is required for normal alveologenesis. To test this hypothesis, we generated a novel transgenic mouse allowing doxycycline-based $m i R-154$ overexpression and analyzed the impact of overexpressing miR-154 in the respiratory epithelium postnatally in normoxic or hyperoxic conditions. Our results indicate that down-regulation of miR-154 in postnatal lungs may function as an important physiological switch that permits the induction of the alveolar developmental program, while conversely, failure to down-regulate miR-154 suppresses alveolarization, leading to the common phenotype of alveolar simplification. Our results support the idea that down-regulation of miR-154 within AT2 cells is an important driver of alveologenesis. 


\section{Material and Methods}

\subsection{Study Approval}

Animal studies: all experiments were approved and performed in accordance with the guidelines from the Federal Authorities for Animal Research of the Regierungspraesidium Giessen, Hessen, Germany (Protocol 21/2013).

\subsection{Mice}

CD1 mice were crossed to generate WT pups. FVB.Cg-Tg(Scgb1a1-rtTA)1Jaw/J (thereafter called $\operatorname{Tg}(\operatorname{Scgb1a1-rtTA}) /+)$ were kindly provided by Anne Karina Perl (Jacksonlab stock number 006232). These mice have been reported to target the respiratory epithelium during embryonic and postnatal stages. They were crossed with $\operatorname{mTg}($ tet $(0) m i R-154) g c$ ) (thereafter called $\mathrm{Tg}($ tet $(0) m i R-154) /+$ ) generated for the need of this study by pronuclear injection of the expression cassette into the blastocysts. Mice were kept on the C57BL/6J background for at least 5 generations. Both genders were used. For induction of the transgene $[\mathrm{Tg}(\operatorname{Scgb1a1-rtTA}) /+; \operatorname{Tg}(\operatorname{tet}(0) \operatorname{miR154}) /+]$ mice were fed with food containing doxycycline (concentration $625 \mathrm{mg} / \mathrm{kg}$, Altromin Spezialfutter GmbH \& Co. KG, Lage, Germany). [Tg(Scgb1a1-rtTA)/+; +/+] littermates (negative for Tg(tet(o)miR154)) were used as control mice. Alternatively, we also used the Rosa2 $6^{r t T A / r t T A}$ mice (for generation of these mice see [25]) to drive ubiquitously miR-154 expression in the lung from E7.5 to E18 [Rosa26 $6^{\text {(rtTA/rtTA) }}$ Tg(tet(o)miR154)/+].

\subsection{Hyperoxia Injury (BPD Mouse Model)}

Newborn pups were subjected to hyperoxia (HOX) $\left(85 \% \mathrm{O}_{2}\right)$ injury from P0-P8 in a chamber (Proox Model 110, Biospherix). To minimize oxygen toxicity and bias, nursing dams were rotated every $24 \mathrm{~h}$ between normoxia (NOX) and HOX. Pups and dams received food and water ad libitum.

\subsection{Left Lobe Perfusion, Isolation and Tissue Processing, Alveolar Morphometry (Mean Linear Intercept, Air Space, Septal-Wall Thickness)}

For newborn mice at P2, P5 and P8, the left lobe was perfused through the trachea with a pressure of $20 \mathrm{~cm} \mathrm{H}_{2} \mathrm{O}$ with $5 \mathrm{~mL}$ PBS followed by $5 \mathrm{~mL} \mathrm{4 \%} \mathrm{PFA.} \mathrm{For} \mathrm{pups} \mathrm{at} \mathrm{E18.5} \mathrm{the} \mathrm{tracheal} \mathrm{perfusion}$ was done by using $10 \mathrm{~cm} \mathrm{H}_{2} \mathrm{O}$ with $1 \mathrm{~mL}$ PBS followed by $1 \mathrm{~mL} \mathrm{4 \%} \mathrm{PFA.} \mathrm{The} \mathrm{trachea} \mathrm{was} \mathrm{tied} \mathrm{off}$ with a string, and the lung was removed and placed in $4 \%$ PFA for max. $24 \mathrm{~h}$ at $4{ }^{\circ} \mathrm{C}$. Lungs were then progressively dehydrated (30\%,50\%,70\%, 99.6\% ethanol, each $3 \mathrm{~h}$ ) and embedded with a Leica embedding machine (EG 1150C, Leica, Wetzlar, Germany). Paraffin blocks were kept cold and $5 \mu \mathrm{m}$ sections were generated.

For alveolar morphometry, lungs were flushed subsequently with PBS and 4\% paraformaldehyde in phosphate-buffered saline ( $\mathrm{pH}$ 7.0) at a vascular pressure of $20 \mathrm{~cm} \mathrm{H}_{2} \mathrm{O}$. Then PBS was infused via the trachea at a pressure of $20 \mathrm{~cm} \mathrm{H}_{2} \mathrm{O}$ and fixed with $4 \%$ paraformaldehyde in phosphate-buffered saline ( $\mathrm{pH} 7.0)$ via the trachea at a pressure of $20 \mathrm{~cm} \mathrm{H} \mathrm{H}_{2} \mathrm{O}$. Investigations were performed using $5 \mu \mathrm{m}$ sections of the paraffin-embedded left lobe of the lungs. The mean linear intercept, mean air space, and mean septal wall thickness were measured after staining with hematoxylin and eosin (HE). Total scans from the left lobe were analyzed using a Leica DM6000B microscope with an automated stage according to the procedure previously described [26,27], which was implemented into the Qwin V3 software (Leica, Wetzlar, Germany). Horizontal lines (distance $40 \mu \mathrm{m}$ ) were placed across each lung section. The number of times the lines cross alveolar walls was calculated by multiplying the length of the horizontal lines and the number of lines per section then dividing by the number of intercepts. Bronchi and vessels above $50 \mu \mathrm{m}$ in diameter were excluded prior to the computerized measurement. The air space was determined as the non-parenchymatous non-stained area. The septal wall thickness was measured as the length of the line perpendicularly crossing a septum. From the respective measurements, mean values were calculated. 


\subsection{RNA Extraction and Quantitative Real-Time RT-qPCR}

After lung function measurements were taken, the right bronchus was clamped and either cranial and accessory or caudal and medial lobes were removed, placed in TRIZOL, homogenized in GentleMACs and frozen in liquid nitrogen for RNA extraction. RNA was isolated using the miRNeasy Mini Kit (Qiagen, Hilden, Germany) according to manufacturer's instructions. RNA was reverse-transcribed (QuantiTect Reverse Transcription Kit, Cat. No. 205313, Qiagen GmbH, Hilden, Germany). cDNA was diluted to a concentration of $5 \mathrm{ng} / \mu$.. Primers were designed using Roche Applied Sciences online Assay Design Tool (Roche Diagnostics Deutschland GmbH, Mannheim, Germany).

All primers were designed to span introns and blasted using NCBI software for specificity. Sybr Green Master Mix (invitrogen, Cat. No.11733-038, Carlsbad, CA, USA) was used for RT-PCR with a Roche LightCycler 480 machine (Roche Diagnostics Deutschland GmbH, Mannheim, Germany). Samples were run in triplicates using Hprt as a reference gene. Mouse primers are listed in supplementary data.

\subsection{Isolation of Primary Alveolar Type II Cells and Microarray Experiments}

Isolation of AT2 cells was performed as previously described [28] with few modifications. Briefly, the whole lung was perfused with $1 \mathrm{~mL}$ PBS through the right ventricle to remove the intrapulmonal blood cells. Lungs were perfused with $1 \mathrm{~mL}$ dispase through the trachea and the trachea was tied off with a string. Lungs were digested in $2 \mathrm{~mL}$ dispase for $30 \mathrm{~min}$ at $37^{\circ} \mathrm{C}$ and minced. The suspension was sequentially filtered through 70, 40, and $10 \mu \mathrm{m}$ nylon meshes and then centrifuged at $200 \times g$ for $10 \mathrm{~min}$. The pellet was resuspended in Dulbecco's modified eagle medium (Invitrogen, Karlsruhe, Germany), and negative selection for endothelial cells and lymphocytes/macrophages was performed by incubation on CD31- and CD45-coated Petri dishes for $45 \mathrm{~min}$ at $37^{\circ} \mathrm{C}$. Negative selection for fibroblasts was performed by adherence for $45 \mathrm{~min}$ at $37^{\circ} \mathrm{C}$ on uncoated cell-culture dishes. Cell purity was analyzed in freshly isolated AT2 cells directly after isolation by epithelial cell morphology and immunofluorescence analysis with Nile red. AT2 cells used throughout this study demonstrated $95 \pm 3 \%$ purity.

RNA from AT2 cells was purified using the RNeasy Mini Kit (Qiagen, Hilden, Germany) following the kit instructions. RNA quality was assessed by capillary electrophoresis using the Bioanalyzer 2100 (Agilent Technologies, Palo Alto, CA, USA). Purified total RNA was amplified and Cy5-labeled using the LIRAK kit (Agilent) following the kit instructions. Per reaction, $200 \mathrm{ng}$ of total RNA was used. The Cy-labeled RNA was hybridized overnight to $8 \times 60 \mathrm{~K} 60$ mer oligonucleotide spotted microarray slides (Agilent Technologies, design ID 028005). Hybridization and subsequent washing and drying of the slides were performed following the Agilent hybridization protocol. The dried slides were scanned at $2 \mu \mathrm{m} /$ pixel resolution using the InnoScan is 900 (Innopsys, Carbonne, France). Image analysis was performed with Mapix 6.5.0 software (Innopsys, 31,390 Carbonne, France), and calculated values for all spots were saved as GenePix results files. Stored data were evaluated using the R software and the limma package from BioConductor (free accessible software, www.r-project.org) [29]. Log mean spot signals were taken for further analysis. Data was quantile-normalized before averaging. Genes were ranked for differential expression using a moderated t-statistic [30]. Pathway analyses were done using gene set tests on the ranks of the $t$-values. We also carried out a gene microarray between experimental [Rosa26 $\left.6^{r t T A) / r t T A} ; \operatorname{Tg}(\operatorname{tet}(0) m i R 154) /+\right]$ and control [Rosa2 $\left.6^{r t T A) / r t T A} ;+++\right]$ lungs (exposed to Dox food from E7.5 to E18) for the selection of potential mRNA targets after the pull-down assay. The data of the microarray experiment are deposited in GEO and are available through the accession number GSE141300 (please note that this SuperSerie is composed of three SubSeries).

\subsection{Immunofluorescence Staining}

Paraffin sections were deparaffinized, blocked with 3\% bovine serum albumin (BSA) and $0.4 \%$ Triton X-100 [in Tris-buffered saline (TBS)] at room temperature (RT) for $1 \mathrm{~h}$ and then incubated 
with primary antibodies against Ki67 (Thermo-Scientific; 1:200), Cdh1/Ecad (BD; 1:100), pro-SFTPC (Seven Hills; 1:100) and pro+mature SFTPB (Abcam; 1:500) at RT for $1 \mathrm{~h}$ or at $4{ }^{\circ} \mathrm{C}$ overnight. After incubation with primary antibodies, slides were washed three times in TBST (TBS buffer $+0.1 \%$ Tween 20) for $5 \mathrm{~min}$, incubated with secondary antibodies at RT for $1 \mathrm{~h}$ and then washed three times in TBST before being mounted with ProLong Gold Antifade Reagent with DAPI (4,6-diamidino-2-phenylindole; Invitrogen). Fluorescent images were acquired using Leica DM5500 B fluorescence microscope connected to Leica DFC360 FX camera (Leica, Wetzlar, Germany).

\subsection{Fluorescence activated Cell Sorting}

Whole lungs were isolated in ice-cold Hank's balanced salt solution (HBSS). Then, lobes were chopped finely using sterile razor blades, digested in a $10 \mathrm{~mL}$ solution of $0.5 \%$ collagenase in HBSS on a heating plate $\left(40^{\circ} \mathrm{C}\right)$ with stirring at $700 \mathrm{rpm}$ for $60 \mathrm{~min}$. Once the homogenate was dissociated, the cell suspension was successively passed through 20G, 24G, and 26G needles, then strained on $70 \mu \mathrm{m}$ and $40 \mu \mathrm{m}$ filters. One volume HBSS was added to dilute collagenase and cell suspensions were centrifuged at $1500 \mathrm{rpm}$ for $5 \mathrm{~min}$ to remove the enzyme solution. Cells were then resuspended in $500 \mu \mathrm{L} \mathrm{10 \%} \mathrm{FCS} \mathrm{in} \mathrm{DMEM} \mathrm{and} \mathrm{stained} \mathrm{with} \mathrm{fluorochrome-labeled} \mathrm{anti-mouse} \mathrm{antibodies} \mathrm{for} 20 \mathrm{~min}$ at $4{ }^{\circ} \mathrm{C}$ (please see supplementary data), followed by washing and flow cytometric analysis with LSR Fortessa equipped with FACSDiva ${ }^{\mathrm{TM}}$ software (BD Bioscience, San Jose, CA, USA). FACS for lung epithelial progenitor cells was performed as previously described [31].

\subsection{Fluorescence In-Situ-Hybridization (FISH)}

$5 \mu \mathrm{m}$ sections of the left lobe of the lung were deparaffinized with Xylene (Carl Roth $\mathrm{GmbH}+$ Co. KG, Karlsruhe, Germany) and a decreasing gradient of Ethanol. After washing the slides with DEPC-PBS the section was digested with Proteinase K (peqlab, Germany). The time of incubation and the concentration of the Proteinase K added to the Proteinase K buffer were dependent on the age of the samples (P2: 1:3000 for $4 \mathrm{~min}$; P5: 1:1300 for $7 \mathrm{~min}$; P8: 1:1300 for $10 \mathrm{~min}$ ). After washing with DEPC-PBS the sections were blocked with Dual endogenous enzyme block (DAKO Envision ${ }^{\mathrm{TM}}+\mathrm{Dual}$ Link System-HRP (DAB+) kit, USA) and then washed again with DEPC-PBS. Then, the sections were incubated in 0.01\% Glutaraldehyde solution (Sigma-Aldrich Chemie GmbH, Germany) diluted in 4\% PFA (Carl Roth GmbH \& Co. KG, Germany) for $10 \mathrm{~min}$ followed by another washing step of DEPC-PBS. The sections were pre-incubated with miRCURY LNA ${ }^{\mathrm{TM}}$ microRNA Detection Hybridization Buffer for $5 \mathrm{~h}$ at $54{ }^{\circ} \mathrm{C}$ before incubation with the miRCURY LNA ${ }^{\mathrm{TM}}$ Detection probe (hsa-miR-154-3p, probe sequence: $5^{\prime}$-AATAGGTCAACCGTGTATGATT-3') diluted in Hybridization Buffer (1:625) for $37 \mathrm{~h}$ at $54{ }^{\circ} \mathrm{C}$. To protect the sections from drying out during incubation, they were covered with HybriWell Incubation chambers (Bio Cat, Germany). The sections were washed with a decreasing gradient of SSC (Sodium/Sodium citrate stock solution 1054.1, Roth, Germany) at $52{ }^{\circ} \mathrm{C}$ and incubated in a blocking solution (DIG Wash and Block Buffer Set, Roche Diagnostics GmbH, Germany) containing 72\% DEPC water, 18\% Maleic acid Buffer 10x and 10\% blocking solution 10x for $30 \mathrm{~min}$ at room temperature. Anti-DIG-POD (ratio 1:400; Roche, Germany) and Sheep Serum (1:250; Dianova, Germany) were added to the blocking solution from the previous step and the section incubated for $4 \mathrm{~h}$ at room temperature. After a last washing step of DEPC-PBS, TSA ${ }^{\mathrm{TM}}$-plus Fluorescein System (Perkin Elmer, Boston, MA, USA) was applied to the section for $15 \mathrm{~h}$. Coverslips were mounted on the slides with Prolong ${ }^{\circledR}$ Gold antifade reagent with DAPI (ProLong ${ }^{\text {TM }}$ Gold antifade reagent with DAPI, P36935, Waltham, MA, USA). Slides were stored at $4{ }^{\circ} \mathrm{C}$ for further analysis.

For quantification, at least 3 histological samples and 5 areas of each sample were used. The number of $m i R-154-3 p$ positive cells ( $m i R-154-3 p$ positive and DAPI positive) was counted and compared to the total number of DAPI positive cells for both bronchiolar and alveolar epithelium. For each sample, a mean value of the number of $m i R-154-3 p$ positive cells was calculated ( $m i R-154-3 p$ positive/DAPI positive cells in relation to DAPI positive cells). Statistical analyses were performed as previously described. 


\subsection{Pull Down Assay with Biotinylated miR-154-3p}

MLE12 cells were cultured in six-well plates and transfected in triplicate with $3^{\prime}$-biotinylated miR-154 (Bio-miR-154) or 3'-biotinylated scramble (Bio-scramble; Dharmacon), at a final concentration of $30 \mathrm{nM}$ using Lipofectamine RNAimax (Invitrogen) following the manufacturer's protocol. After $48 \mathrm{~h}$, the cells were pelleted at $1000 \mathrm{rpm}$ for $5 \mathrm{~min}$. After washing twice, cell pellets were resuspended in $0.5 \mathrm{~mL}$ lysis buffer [50 mM Tris- $\mathrm{HCl}, 2 \mathrm{mM}$ EDTA, 0.1\% NP40, 10\% glycerol, $2 \mathrm{mM}$ EGTA, diethylpyrocarbonate (DEPC)-treated water, $50 \mathrm{U}$ RNasin (Promega) and complete mini-protease inhibitor cocktail (Roche Applied Science)], and incubated at $4{ }^{\circ} \mathrm{C}$ for $10 \mathrm{~min}$. The cytoplasmic extract was isolated by centrifugation at 10,000 rpm for $10 \mathrm{~min}$. Streptavidin-coated magnetic beads (Invitrogen) were blocked for $1 \mathrm{~h}$ at $4{ }^{\circ} \mathrm{C}$ in blocking buffer $(10 \mathrm{mM}$ Tris- $\mathrm{HCl} \mathrm{pH}$ 6.5, $1 \mathrm{mM}$ EDTA, $1 \mathrm{mg} / \mathrm{mL}$ yeast tRNA and $1 \mathrm{mg} / \mathrm{mL}$ BSA) and washed twice with $1 \mathrm{~mL}$ washing buffer $(10 \mathrm{mM}$ Tris- $\mathrm{HCl}$ pH 6.5, $1 \mathrm{mM}$ EDTA $0.5 \mathrm{M} \mathrm{NaCl}$ ). Beads were resuspended in $0.5 \mathrm{~mL}$ washing buffer. Cytoplasmic extract was then added to the beads and incubated for $1 \mathrm{~h}$ at $4{ }^{\circ} \mathrm{C}$ with slow rotation. The beads were then washed five times with $1 \mathrm{~mL}$ washing buffer. RNA bound to the beads (pull-down RNA) or from $10 \%$ of the extract (input RNA), was isolated using Trizol reagent LS (Invitrogen). The level of mRNA in the Bio-miR-154 or Bio-scramble control pull-down was quantified by qPCR. mRNA levels were normalized to a housekeeping gene $(\mathrm{Gapdh}, \mathrm{H4})$. The enrichment ratio of the control-normalized pull-down RNA to the control-normalized input levels was then calculated. The data for each cell line are representative of three independent experiments. The isolated RNA was processed for gene array analysis as described above. The data of the gene array experiment are deposited in GEO and are available through the accession number GSE141300.

\subsection{Statistical Analyses}

Significance was determined by two-tailed Student's t-test using GraphPad PRISM statistical analysis software. All data are presented as mean \pm SEM. Values of $p<0.05$ were considered significant.

\section{Results}

\subsection{Normal Postnatal Decrease of miR-154-3p Expression Is Prevented by Hyperoxia Treatment}

We have examined by qPCR, the expression of miR-154-3p in the embryonic lung at different developmental stages (between E10.5 and adult). Figure 1A indicates that the expression of $m i R-154-3 p$ steadily increases during development (from E10.5 to P2) but is decreased in adult mice. Fluorescence in situ hybridization on sections show that expression of miR-154-3p at E17.5 and P2, is located both in the bronchiolar epithelium and in the parenchyma (Figure 1B). Exposure of neonate mice to either hyperoxia (HOX) or normoxia (NOX) for 8 days indicate that under NOX conditions, the expression of $m i R-154-3 p$ progressively disappears from both the alveolar and bronchiolar compartment at P8. By contrast, the expression of $m i R-154-3 p$ is maintained in these two compartments in HOX treated lungs (Figure 1C). Quantification by qPCR of the expression of miR-154 isoforms (miR-154-3p and $m i R-154-5 p$ ) confirmed that at $\mathrm{P} 2$, the $3 p$ isoform was significantly increased upon HOX treatment. A trend towards an increase was also observed for this isoform at P5 and P8. No difference at the level of the whole lung was detected for the $5 p$ isoform (Figure 1D). Finally, we isolated alveolar type 2 (AT2) cells by FACS and detected by qPCR an increase in the expression of both isoforms in HOX versus NOX ( $p=0.0015$ and 0.02 for the $3 p$ isoform and $5 p$ isoform, respectively). These data suggest that down-regulation of $m i R-154$ in AT2 cells could be important to facilitate alveologenesis. 
A

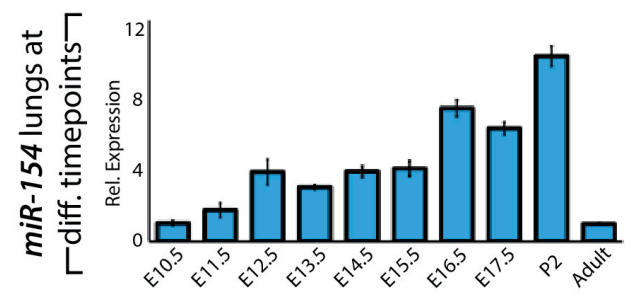

B

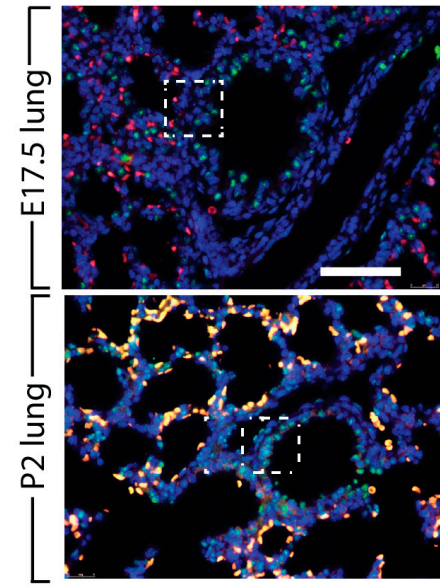

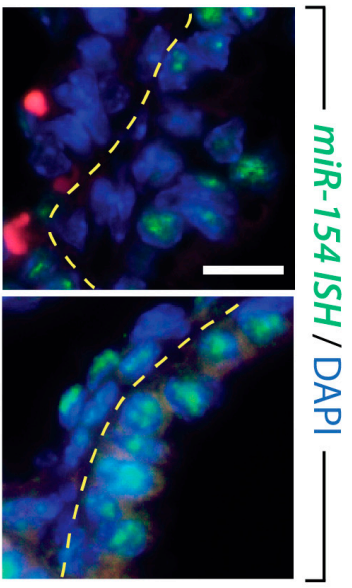

C
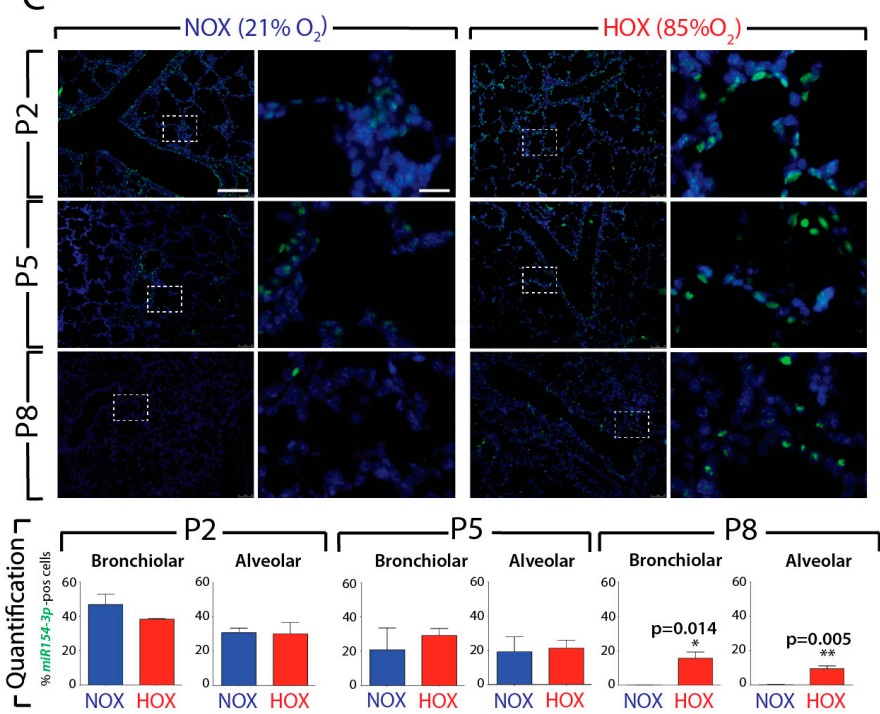

P5

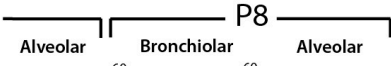

.

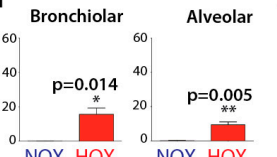

D
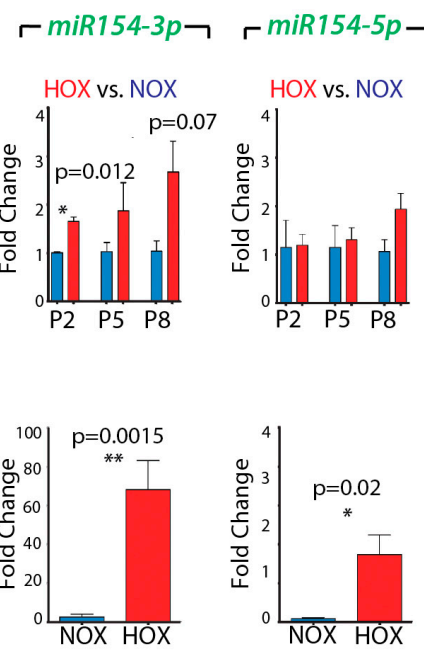

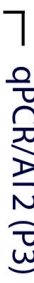

Figure 1. Expression of $m i R-154-3 p$ and $m i R-154-5 p$ during development and after hyperoxic lung injury: A. Expression of $m i R-154-3 p$ in the lung from E10.5- adult age. B. FISH of $m i R-154-3 p$ expression at E17.5 and P2. C. miR-154-3p expression in hyperoxic lung injury at P2, P5 and P8 by FISH and Quantification of miR-154-3p positive cells in bronchiolar and alveolar epithelium. D. miR-154-3p and miR-154-5p expression in whole lung and isolated AT2 cells by RT-qPCR. Please note: for each stage the expression of $m i R-154-3 p$ and $-5 p$ in the hyperoxia have been normalized to the expression in normoxia. P2: $\operatorname{NOX}_{n}=2, \operatorname{HOX} n=3 ;$ P5: $\operatorname{NOX}_{n}=3, \operatorname{HOX} n=4 ;$ P8: NOX $n=3, \operatorname{HOX} n=3$; P3: NOX $n=6$, HOX $\mathrm{n}=6$. Scale bar in B: low magnification: $120 \mu \mathrm{m}$; high magnification: $30 \mu \mathrm{m}$. Scale bar C: low magnification: $180 \mu \mathrm{m}$; high magnification: $45 \mu \mathrm{m} .{ }^{*} p \leq 0.05,{ }^{* *} p \leq 0.01,{ }^{* * *} p \leq 0.001,{ }^{* * * *} p \leq 0.0001$.

\subsection{Generation and Validation of a Mouse Transgenic Model Allowing Postnatal miR-154 Overexpression}

In order to test whether down-regulation of $m i R-154$ is required for normal alveologenesis, we generated a mouse model allowing doxycycline-based induction of miR-154 expression ( $T g(m i R-154))$ (Figure 2A). As we used pronuclear injection as a mean to generate the transgenic animals, we next checked the site of integration of the expression cassette. We found that one copy of this cassette integrated near the Sorting Nexin 19 (Snx19) gene. The integration of the miR-154 cassette did not perturb the expression of $\operatorname{Snx} 19$ (Figure 2B). To functionally validate the use of the $\operatorname{Tg}(\mathrm{miR}-154)$ to upregulate miR-154 expression, we crossed the $T g(S c g b 1 a 1-r t T A) / T g((S c g b 1 a 1-r t T A)$ driver mice (to target the respiratory epithelium, Jacksonlab, strain number 006242) with the $T g(m i R-154) /+$ mice (Figure 2C). We exposed the pregnant females from E18.5 and the lactating mothers (with their progeny) to 
doxycycline food up to P16. We then collected the control $[\mathrm{Tg}((\operatorname{Scgb1a1-rtTA}) /+;+/+]$ and experimental $[\operatorname{Tg}(($ Scgb1a1-rtTA $) /+; \operatorname{Tg}(\mathrm{miR}-154) /+]$ lungs at P16. Analysis by qPCR indicates a significant upregulation of both miR-154 isoforms in experimental versus control lungs (Figure 2D).

A

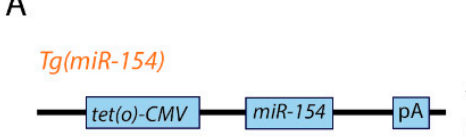

B

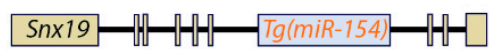

$E$

Biotinylated miR-154/mRNA pull down followed by RNA seq

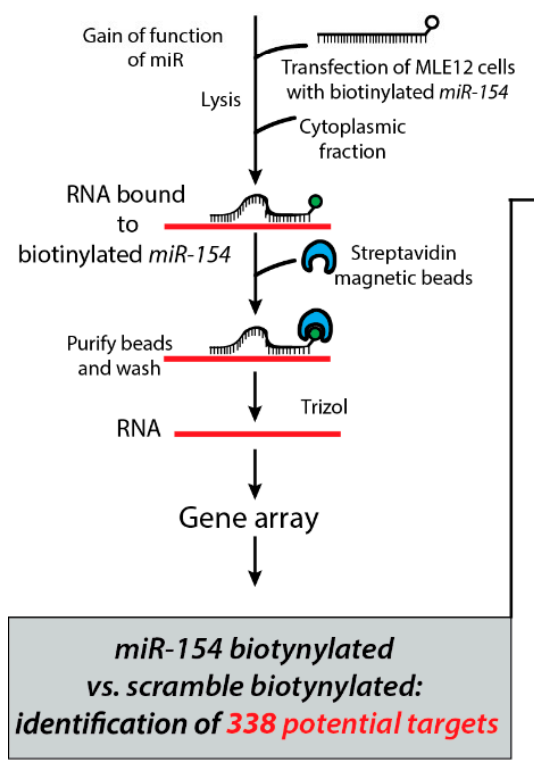

C $\operatorname{Tg}($ scgb1a1-rtTA)/Tg(Scgb1a1-rtTA) $\operatorname{Tg}($ miR-154)/+

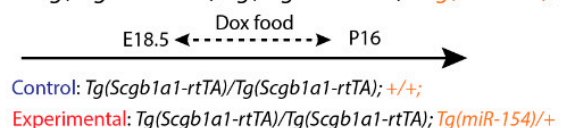

Experimental: $\operatorname{Tg}(\mathrm{Scgb1a1}-\mathrm{rtTA}) / \operatorname{Tg}(\mathrm{Scgb1a1}$-rtTA); $\operatorname{Tg}(\operatorname{miR}-154) /+$
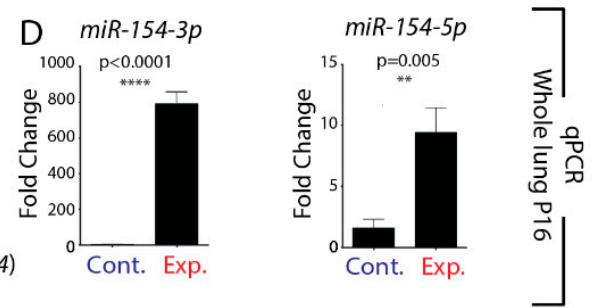

$\mathrm{G}$

Gain of function experiment in vivo (dox food E7.5-E18.5) (Rosa26 $6^{\text {tTARITA; }} \operatorname{Tg}(\operatorname{miR}-154) /+$ )

\section{7 refined targets}

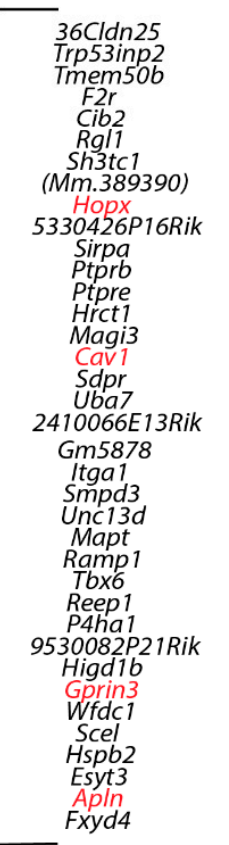

Figure 2. Generation/validation of transgenic mice for miR-154 overexpression and pull-down assay. A. Scheme of miR-154 transgene and genotyping results from $\operatorname{Tg}(\operatorname{tet}(\mathrm{O}) \mathrm{miR}-154)$ mice. B. Scheme of Snx19 gene and the Tg integration site. Expression of Snx19 after Tg integration was analyzed by qPCR in embryonic lungs. C+D. Increased expression of $m i R-154-3 p$ and $m i R-154-5 p$ in double transgenic mice $[T g((S c g b 1 a 1-r t T A) /+; \operatorname{Tg}(m i R-154) /+]$ versus WT $[T g((S c g b 1 a 1-r t T A) /+;+/+]$ after Dox induction from E18 to P16. E-G. Pull down biotinylated miR-154 versus gain of function with mimic in MLE12

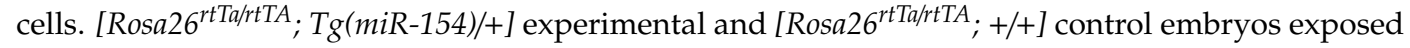
to Dox in utero from E7.5 to E18.5 were generated and the lungs collected for genearray analysis to identify the genes downregulated upon miR-154 overexpression. ${ }^{*} p \leq 0.05,{ }^{* *} p \leq 0.01,{ }^{* * *} p \leq 0.001$, ${ }^{* * * * *} p \leq 0.0001$.

\subsection{Identification of Potential miR-154 Targets Using a Biotinylated Pull-Down Assay Followed by} Gene Arrays

Next, we wanted to identify the miR-154-3p mRNA target genes. For this purpose, we performed a pull-down experiment using a biotinylated $m i R-154-3 p$ followed by gene array to identify these targets (Figure 2E). We used scrambled biotinylated miR as a control and identified 338 potential targets 
(deposited in GEO, accession number GSE141300). As a next step, we also identified in the miR-154 overexpressing lungs (compared to control lungs), the downregulated gene products, which we propose may contain miR-154 targets (Figure 2F). We overexpressed miR-154 ubiquitously in the developing lung by exposing the pregnant females carrying both experimental [Rosa26 ${ }^{\text {rtTA)/rtTA; }}$ Tg(tet(o)miR154)/+] and control [Rosa26 $\left.\left.{ }^{r t T A}\right) / r t T A ;++\right]$ embyos to Dox food from E7.5 to E18). Experimental and control E18 lungs were isolated, RNA was extracted and processed for gene arrays. The intersection between the genes identified in the pull-down assay and the genes downregulated in the lungs overexpressing ubiquitously miR-154 allowed the identification of 37 refined targets (Figure 2G). Among them we found Caveolin1 (Cav1) as well as Homeodomain protein homeobox (Hopx), G protein-regulated inducer of neurite outgrowth 3 (Gprin3) and Apelin (Apln).

Cav1 has been shown to be downregulated by Tgf- $\beta 1$ via p38/MAPK, thereby inducing proliferative and anti-apoptotic properties in myofibroblasts [32]. In murine small intestine, Fgf10 downregulates the expression of the stem cell marker Hopx [33]. Furthermore, and most interestingly, Hopx expression was shown in the bipotent alveolar epithelial cell progenitor and in AT1 cells, but not AT2 cells, suggesting Hopx as a marker gene for AT1 cells [34]. Gprin3 was found to be regulated by Fgf10 during early lung development (Bellusci and Jones, data not published). In humans, it was shown that APLN indirectly regulates the expression of FGF2 and FGFR1 in pulmonary arterial hypertension via its microRNA mediators $m i R-424$ and $m i R-503$ [35]. We propose that the regulation of some of these targets in the alveolar epithelium (mostly the AT2 cells) could be responsible for the phenotype associated with $m i R-154$ overexpression.

3.4. miR-154 Overexpression in the Lung Epithelium Postnatally under Normoxic Conditions is Sufficient to Impair Alveologenesis

Our results suggested that down-regulation of miR-154 in AT2 cells could be important to facilitate alveologenesis. In order to test this hypothesis, we generated a transgenic mouse mode where miR-154 was induced in the alveolar epithelium upon doxycycline exposure. We used the $[T g(S c g b 1 a 1-r t T A) / T g(S c g b 1 a 1-r t T A)]$ mice previously described to target the respiratory epithelium and crossed them with the $T g(m i R-154) /+$ mice. We generated control $[T g(S c g b 1 a 1-r t T A) / T g(S c g b 1 a 1-r t T A)$; +/+] and experimental [ $T g(\operatorname{Scgb1a1-rtTA}) / \operatorname{Tg}(\operatorname{Scgb1a1-rtTA}) ; \mathrm{Tg}(\mathrm{miR}-154) /+]$ neonates and exposed them from P0 to P16 to doxycycline food in NOX conditions (Figure 3A). At P16, the animals were euthanized and the lungs ( $n=5$ and 4 for control and experimental, respectively) were isolated for morphometry analysis as well as for gene expression. Figure 3B indicates that experimental lungs display an increase in the size of the respiratory airway units. Morphometry analysis indicates increased mean linear intercept (MLI) $(p=0.0022)$ without any significant change in airspace $(p=0.2111)$ and septal thickness $(p=0.9730)$ (Figure 3C).

Next, we used qPCR to determine potential changes in Fgf signaling, Tgf- $\beta$ signaling as well as in epithelial and alveolar myofibroblasts (MYF) markers (Figure 3D). Our data suggest an increase in Fgf signaling upon miR-154 overexpression in the distal epithelium Interestingly, among the significantly upregulated genes, we found Fgfr1b $(p=0.0028)$, Etv4 $(p=0.0021)$ and Sprouty4 $(p=0.0412)$, which have been described to be expressed also in the lung mesenchyme [36-38]. The analysis of the epithelial markers showed that Aquaporin 5 (Aqp5) is increased, even though it did not reach significance $(p=0.0685)$. We also found evidence for increased $T g f-\beta$ signaling as indicated by upregulation of Tgf- $\beta 3$ and Sma mother against decapentaplegic (Smad7) $(p=0.0394)$. Plasminogen activator inhibitor type $1(P a i-1)$ as a downstream target of $T g f-\beta$ signaling was upregulated but did not reach statistical significance $(p=0.0585)$. In addition, we did not observe any significant change at the level of the alveolar MYF markers. 
A

$+\operatorname{dox}\left(\right.$ Normoxia $21 \% \mathrm{O}_{2}$ )
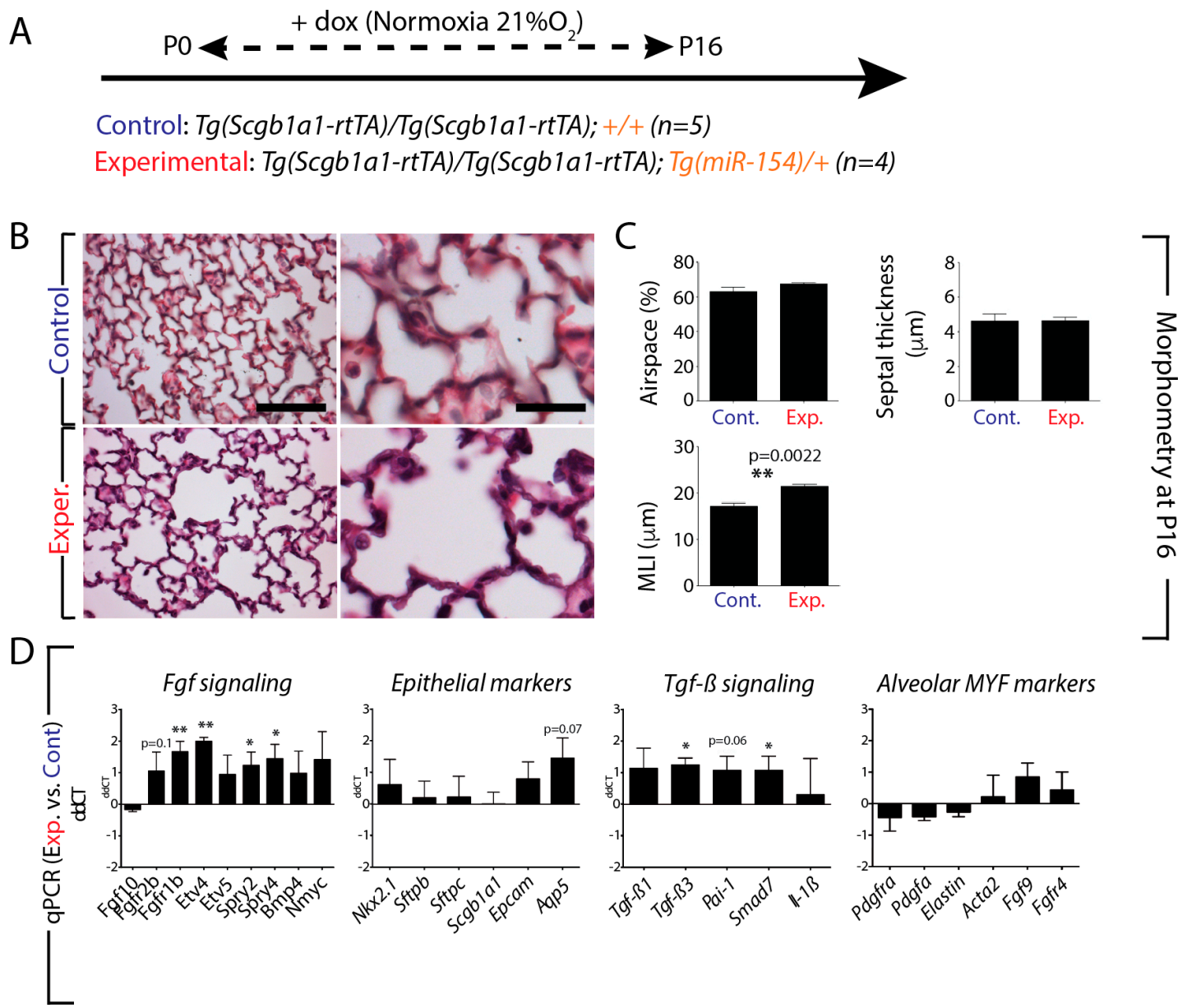

Figure 3. Effect of miR-154 overexpression on lung morphology and gene expression: A. Model of transgenic induction of miR-154 expression by doxycycline (Dox) administration. B. Experimental lungs display an increase in the size of the respiratory airway units. C. Alveolar Morphometry shows impaired alveolar development after miR-154 overexpression indicated by increased MLI. D. RT-qPCR analysis reveals dynamically altered genetic expression profiles upon miRNA overexpression. $F g f$ signaling, Tgf- $\beta$ signaling and epithelial cell markers appear to be affected in an opposite manner as under hyperoxic conditions (compare to Figure 6C), although significance is not reached concerning $T g f-\beta$ signaling. Interestingly, unlike hyperoxia, genes linked to alveolar myofibroblasts do not show any significant alterations upon miRNA Induction. Scale bar in B: low magnification: $125 \mu \mathrm{m}$; high magnification: $50 \mu \mathrm{m} .{ }^{*} p \leq 0.05,{ }^{* *} p \leq 0.01,{ }^{* * *} p \leq 0.001,{ }^{* * * *} p \leq 0.0001$.

3.5. Identification of Genes Regulated in AT2 Cells from Experimental Versus Control Lungs and Analysis of AT2 Cell Differentiation

At P16, at the end of the treatment with doxycycline under normoxia conditions, we isolated alveolar type 2 airway epithelial cells (AT2) by FACS from control $(n=4)$ and experimental $(n=4)$ mice and carried out gene arrays (Figure 4A). Figure 4B shows a heatmap representation of the most significantly regulated genes. KEGG analysis indicated that several pathways were significantly affected such as focal adhesion, PI3K-AKT pathway, extracellular matrix-receptor interactions and the Hippo signaling pathway (Figure 4C). Next, we monitored the expression of AT1 and AT2 markers using gene array analysis. The heatmap showed that the expression of AT1 markers, such as Pmp22, Dpysl2, Cav1, Hopx were significantly increased upon miR-154 overexpression compared to control AT2 cells. Interestingly, the expression of AT2 markers were significantly decreased although they appeared to be inconsistently altered (Figure 4D, E). Volcano plot also indicated increased AT1 signature in AT2 cells from miR-154 overexpressing mice compared to control AT2 cells (Figure 4F). 

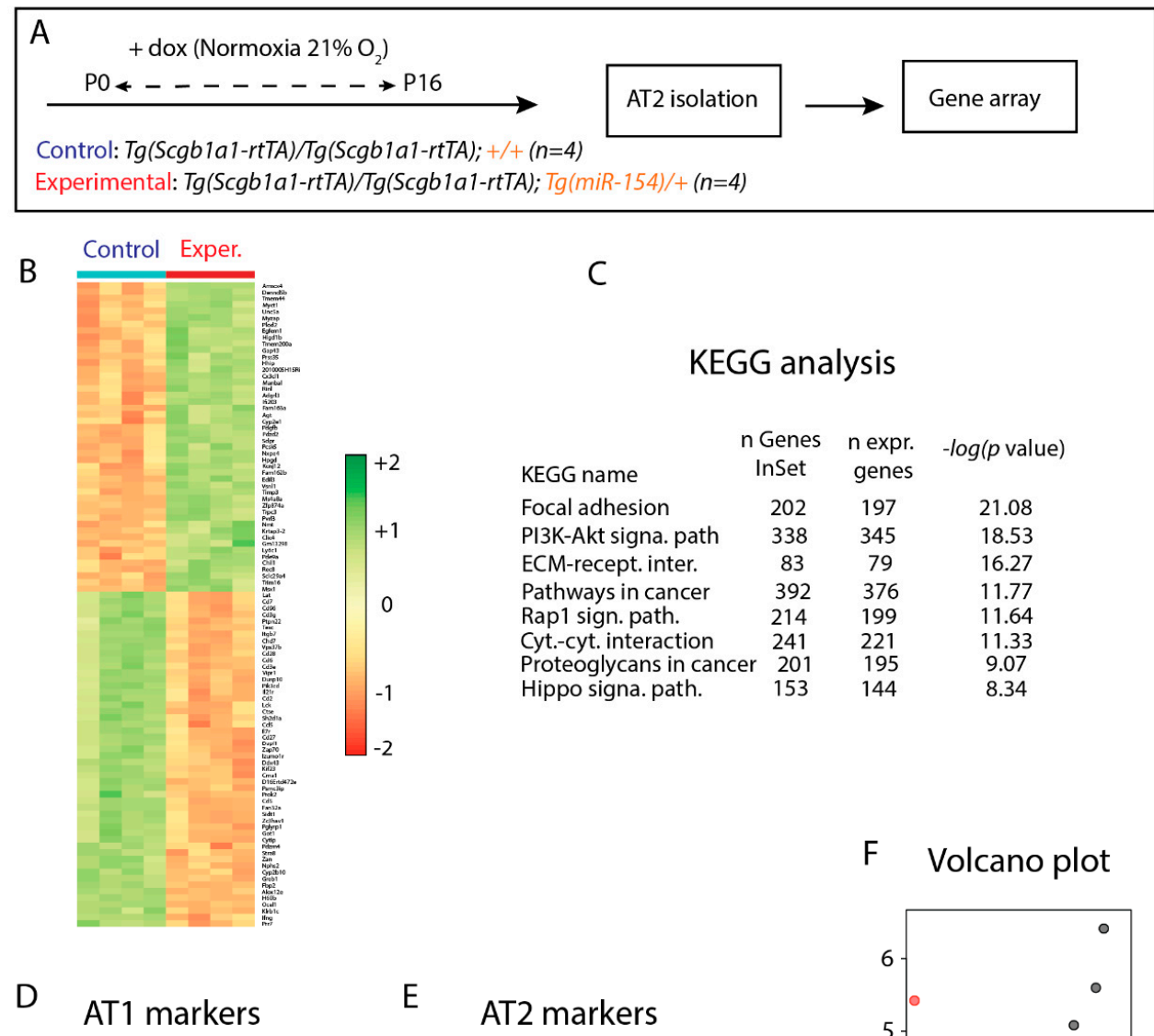

\section{$\mathrm{E}$}
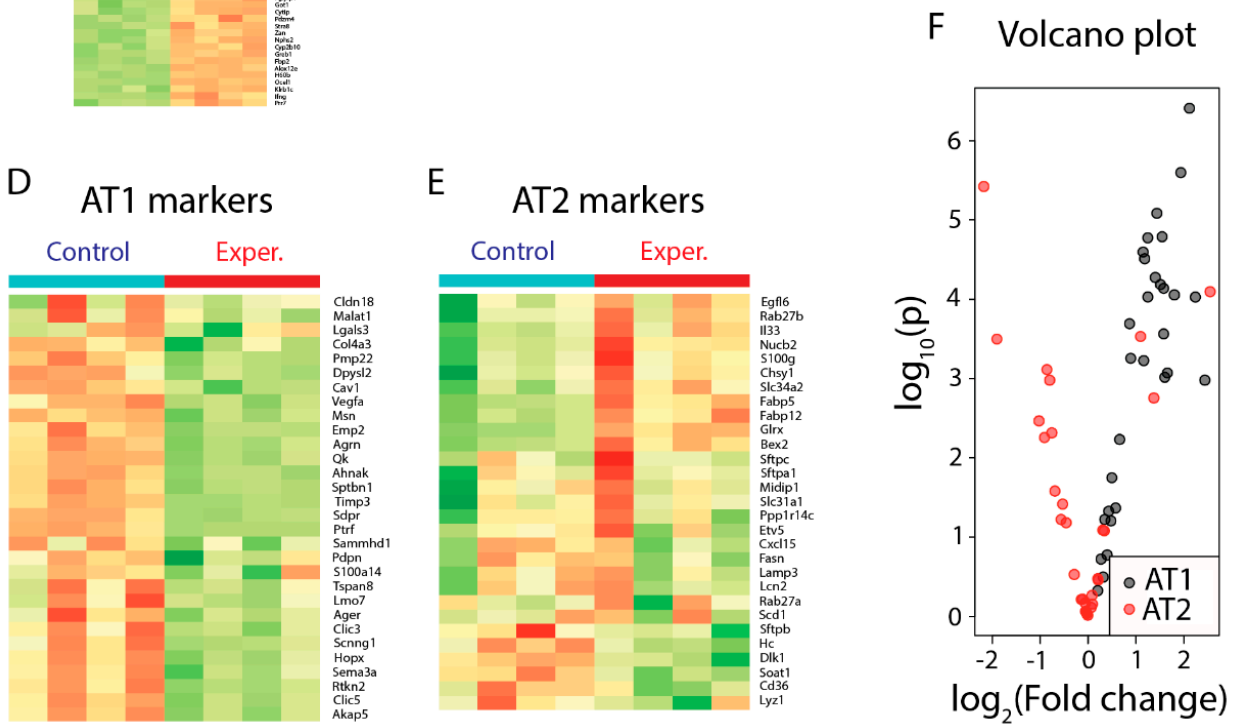

Figure 4. Gene Array Analysis performed on isolated AT2 samples: A. Model of miR-154 induction by doxycycline administration. B. Differentially expressed genes upon miRNA overexpression. C. KEGG Analysis. D. Differential regulation of AT1 markers. AT1 markers appear to be increased in expression levels upon miR-154 overexpression (Exper.) compared to control. E. Differential regulation of AT2 markers. AT2 markers appear to be inconsistently altered in expression levels upon miR-154 overexpression (Exper.) compared to control. F. Volcano plot demonstrating the increased AT1 signature in isolated AT2 cells after miRNA induction compared to Control. For control and experimental $\mathrm{n}=4$.

\subsection{Increased Tgf- $\beta$ Signaling in Experimental Versus Control Lungs in Normoxia}

Two read outs of Tgf- $\beta$ signaling are Caveolin1 (Cav1) and P-Smad3. Caveolin1 is a structural protein within caveolar membranes. This protein is important for caveolae formation from lipid rafts. Cav1 inhibits Tgf- $\beta$ signaling by promoting Tgf- $\beta$ R 1 removal from the membrane and its degradation [39]. Smad3 is a downstream transducer of Tgf- $\beta$ signaling as well as a transcriptional modulator. The phosphorylation of Smad3 is among the first events occurring during the activation of the Tgf- $\beta$ pathway. Next, we quantified via immunofluorescence (IF) the level of expression of Cav1 
and P-Smad3 in the lung tissues from control and experimental mice at P16 under NOX condition (Figure 5). Analysis of Cav1 expression indicated a significant decrease in its expression in the experimental versus control lungs (Figure 5A). Quantification of pixel intensity of Cav1-positive cells is consistent with this observation (Figure 5B). We found less cells beyond the 5000 (arbitrary units) threshold ( $26 \%$ versus $54 \%$, in experimental versus control lungs, respectively). Next, we examined the expression level of P-Smad3. The IF images suggest increased expression of P-Smad3 in the experimental lungs (Figure 5C). Quantification of pixel intensity of P-Smad3 positive cells supports this observation. We found that more cells displayed increased pixel intensity beyond the 25,000 (arbitrary units) threshold (54.1\% versus $43.2 \%$ in experimental versus control lungs, respectively) (Figure 5D). In addition, the dynamic range of the intensity also increased in the experimental lungs (from 25,000 to 75,000 in the control versus 25,000 to 100,000 in the experimental).

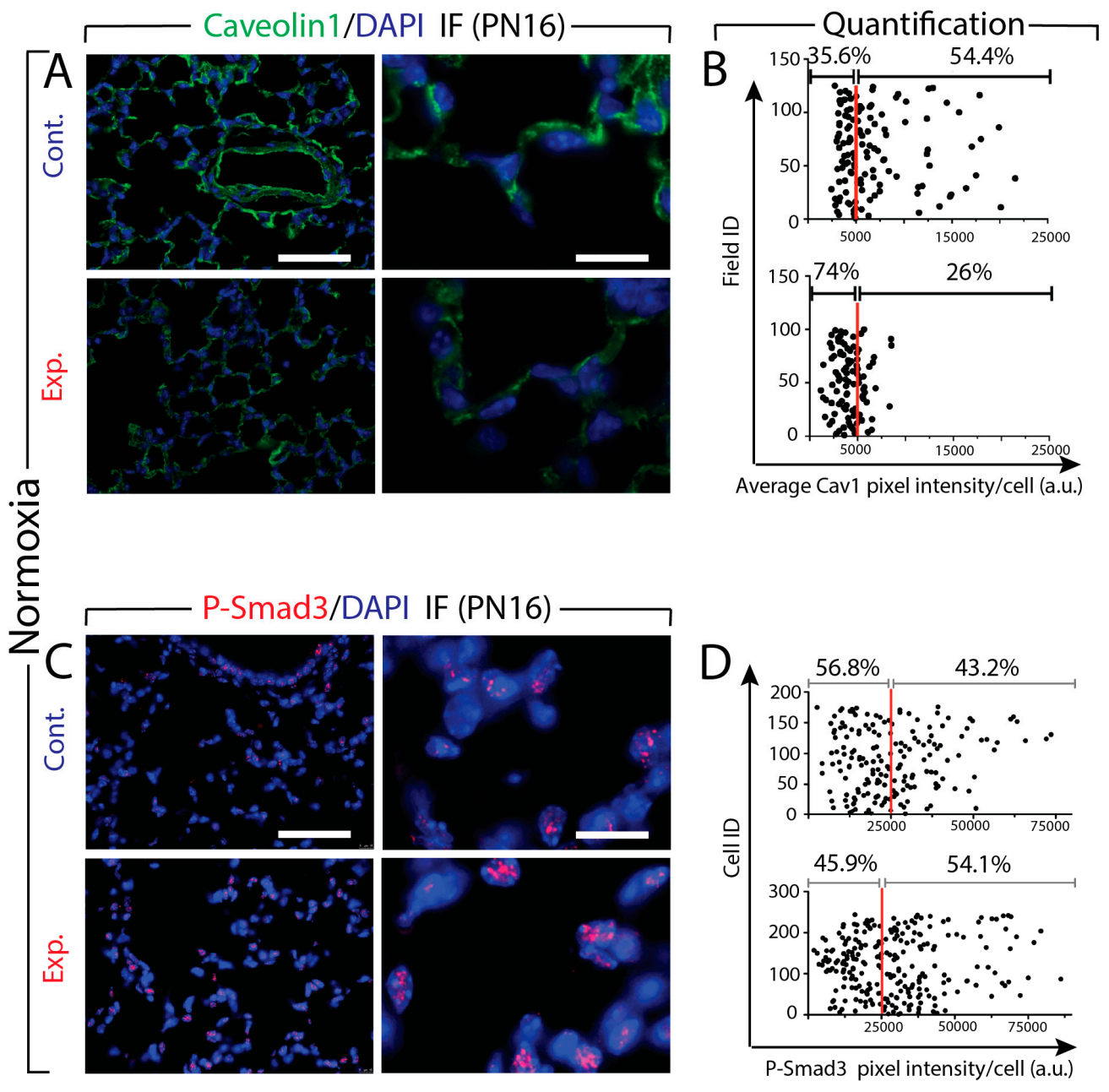

Figure 5. Expression of Cav1 and P-Smad3 proteins in the lung tissues from control (Cont.) and experimental (Exp.) mice at P16 under NOX condition. A. IF images show a decreased expression of Cav1 in the experimental lungs. B. Quantification of pixel intensity of Cav1 positive cells indicates a significant decrease of Cav1 expression in the experimental mice. C. The IF images show an increased expression of P-Smad3 in the experimental lungs. D. Quantification of pixel intensity of P-Smad3 positive cells supports the IF images in C. Scale bar A and C: low magnification: $180 \mu \mathrm{m}$; high magnification: $45 \mu \mathrm{m}$. 
3.7. Upon Hyperoxia Injury, Key Signaling Pathways Were Differentially Affected between the miR-154 Overexpressing Lungs Versus Control Lungs, But the Alveolar Simplification Phenotype in Both Cases Was Morphologically Indistinguishable

To explore the role of hyperoxic lung injury in combination with overexpression of $m i R-154$ on the process of alveologenesis, we exposed control and experimental mice to HOX injury for the first 8 days and then put our mice back on NOX conditions until P16 (Figure 6A). H\&E and morphometric analysis indicate no significant difference between control and experimental lungs (Figure 6B). qPCR analysis using RNA extracted from the whole lung indicated a trend towards a decrease in $F g f$ signaling associated with a decrease in markers of the alveolar epithelium such as $N k x 2.1$ and Sftpb $(N k x 2.1 p=0.0363 ; S f t p b p=0.0461)$. For the alveolar markers, we also noticed an increase in Fgfr4 $(p=0.0102)$ and a trend towards an increase for Pdgfra $(p=0.0535)$ (Figure 6C). Next, we compared the differences between HOX and NOX in control and experimental lungs (Figure 6D). Figure 6E shows the results for the control mice. We observed a global increase in Fgf signaling ( Fgfr $2 b p=0.0015$; Fgfr1b $p=0.0022$; Etv4 $p=0.0048$; Nmyc $p=0.0188$; Spry2 $p=0.0478$ ) as well as the associated alveolar epithelial markers $S f t p b(p=0.0220), \operatorname{Epcam}(p=0.0461)$ and Aqp5 $(p=0.0060)$. Tgf- $\beta$ signaling was also increased (Tgf- $\beta 3 p=0.0018$; Tgf- $\beta 1 p=0.0073$; Smad7 $p=0.0439)$. Elastin and Fgf9, two markers of the alveolar myofibroblasts were also increased (Elastin $p=0.0063 ;$ Fgf9 $p=0.0114$ ). Morphometric analysis indicates increased MLI as expected (data not shown). Figure 6F shows the results for experimental mice. Our results indicated that the effect of HOX normally observed in control lungs was cancelled by $m i R-154$ overexpression. No significant changes were observed for Fgf signaling, the epithelial markers and Tgf- $\beta$ signaling. The only exception was in the alveolar markers Elastin and Fgf9, which appeared to be upregulated upon HOX exposure in the mutant lungs (Fgf9 $p=0.0101$; Shh $p=0.0195$; Elastin $p=0.0519)$. These results suggest that the expression of these markers is independent of $m i R-154$ upregulation (Figure 6F). In line with the gene expression, the morphometric analysis indicated no differences in airspace, septal wall thickness and MLI between the HOX and NOX in experimental mice (data not shown).

\subsection{Increased Tgf- $\beta$ Signaling in miR-154 Experimental Versus Control Lungs in Hyperoxia}

Next, we quantified via immunofluorescence (IF) the level of expression of Cav1 and p-Smad3 in the lung tissues from control and experimental mice at P16 under HOX condition (Figure 7). The analysis of Cav1 expression indicated a significant decrease in its expression in the experimental versus control lungs (Figure 7A). Quantification of pixel intensity of Cav1 positive cells is consistent with this observation. We found less cells beyond the 5000 (arbitrary units) threshold (7\% versus $31 \%$, in experimental versus control lungs, respectively) (Figure 7B). The IF images also suggest increased expression of P-Smad3 in the experimental lungs (Figure 7C). However, the quantification of pixel intensity of P-Smad3 positive cells showed that the same percentile of cells (54\% versus 55\% in experimental versus control lungs, respectively) beyond the previously established 25,000 (arbitrary units) threshold (Figure 7D). Interestingly, as for the comparison of the effect of NOX (Figure 5), the dynamic range of the intensity also increased in the experimental lungs (from 25,000 to 75,000 in the control versus 25,000 to 100,000 in the experimental). Altogether, these data suggest that there is more Tgf- $\beta$ signaling occurring in the experimental versus control lung but the percentile of cells showing signs of Tgf- $\beta$ signaling in experimental and control lungs is the similar. 

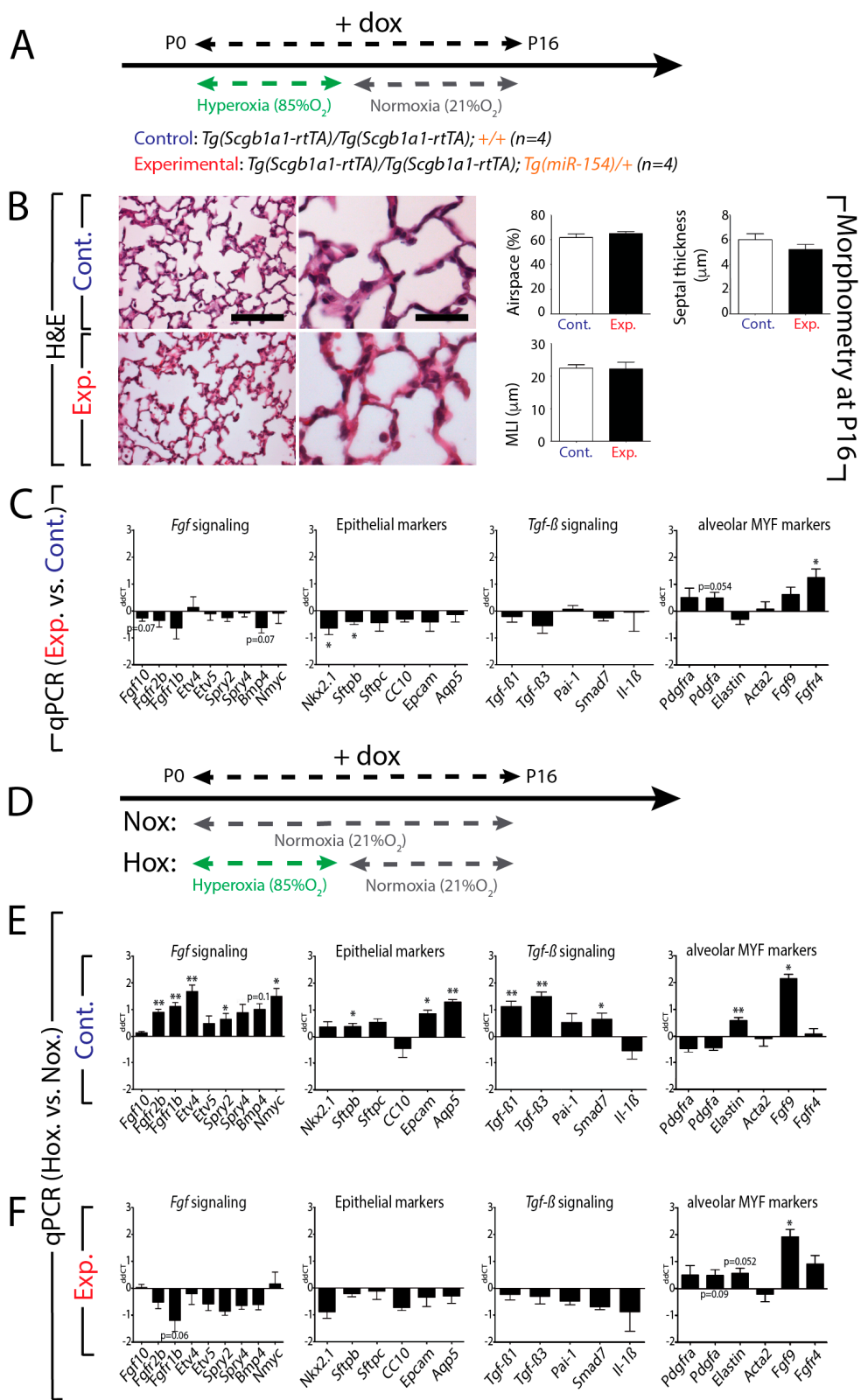

Figure 6. Hyperoxic lung injury on top of overexpression of miR-154 (double injury) compared to miRNA overexpression only (single injury): A. Model of hyperoxic treatment and doxycycline (Dox) administration in order to activate miR-154 overexpression. B. Alveolar Morphometry reveals no further effect of double injury (hyperoxia and miRNA overexpression) on alveolar parameters compared to single injury ( $m i R N A$ overexpression only). C. RT-qPCR data show no obvious effect of additional hyperoxic injury on top of $m i R-154$ overexpression for $F g f$ signaling, $T g f-\beta$ signaling and epithelial cell markers. Merely genes connected to alveolar myofibroblast formation and function seem to be affected by additional hyperoxic exposure. (HOX and NOX each $n=4$ ). D. Model of either normoxia or hyperoxia treatment in control and experimental mice. E. RT-qPCR analysis in the control mice reveals a global increase in Fgf signaling as well as the associated alveolar epithelial markers (Sftpb, Epcam and Aqp5), Tgf- $\beta$ signaling was also increased (Tg-f $\beta 1, T g f-\beta 3$, Smad7). F. The data from experimental mice suggest no significant changes for $F g f$ signaling, the epithelial markers and Tgf- $\beta$ signaling. Scale bar in B: low magnification: $125 \mu \mathrm{m}$; high magnification: $50 \mu \mathrm{m} .{ }^{*} p \leq 0.05,{ }^{* *} p \leq 0.01,{ }^{* * *} p \leq 0.001$, $* * * * p \leq 0.0001$. 


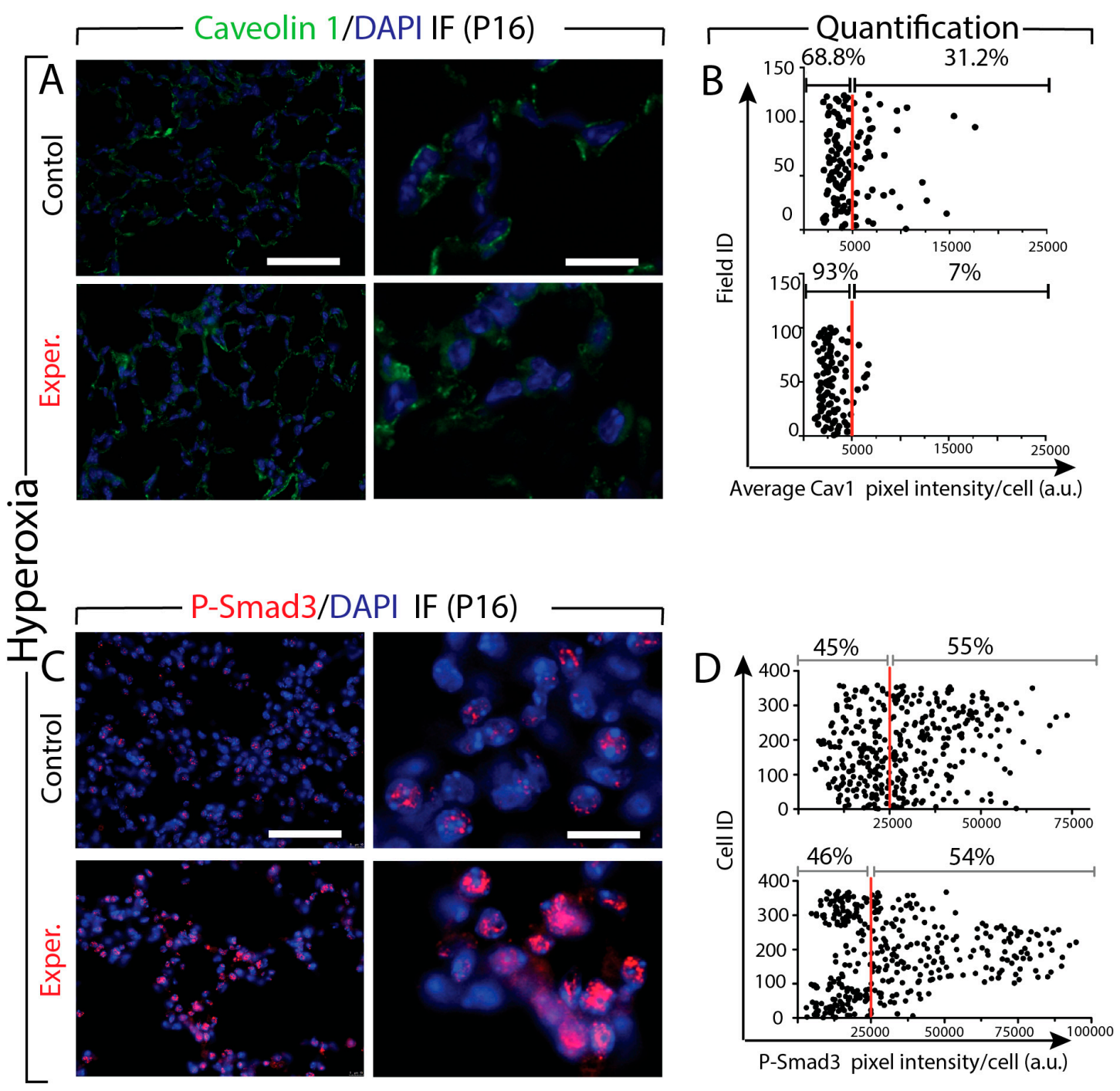

Figure 7. Effect of hyperoxia on the expression of Cav1 and P-Smad3 protein in the lung tissues from control and experimental mice. A. IF images show decrease of Caveolin1 expression. B. Quantification of pixel intensity of Cav1 positive cells indicates a significant decrease of Cav1 expression in the experimental mice. C. The IF images show an increased expression of P-Smad3 in the experimental lungs. D. The quantification of pixel intensity of P-Smad3 positive cells show the same percentile of cells between experimental versus control lungs. Scale bar in A and C: low magnification: $45 \mu \mathrm{m}$; high magnification: $180 \mu \mathrm{m}$.

\section{Discussion}

Our data demonstrate that endogenous miR-154 expression is normally downregulated in the distal lung epithelium after birth. However, persistent expression of $m i R-154$ was observed in AT2 cells isolated from postnatal lungs exposed to HOX versus NOX suggesting that downregulation of miR-154 in AT2 could be important to facilitate the induction of alveologenesis. To test this hypothesis, we generated a novel miR-154 gain of function transgenic mouse to overexpress miR-154 in the airway epithelium. miR-154 overexpression in the alveolar epithelium using the $\operatorname{Tg}(S c g b 1 a 1-r t T A)$ driver line under normoxic conditions is sufficient to prevent alveolarization and triggers alveolar simplification as reflected by increased MLI. Using a pull down assay with biotinylated miR-154, we identified Cav1 as a primary functional target for $m i R-154$. We further demonstrated that Cav1 protein expression is decreased in miR-154 experimental versus control lungs. This is associated with increased Tgf- $\beta 1$ signaling as shown by the upregulation of P-Smad3 levels. Increased Tgf- $\beta 1$ signaling in the lung at 
birth is associated with a BPD-like phenotype of alveolar simplification. Our conclusion that miR-154 overexpression leads to enhanced Tgf- $\beta$ signaling in the lung which could be causative for the BPD-like alveolar simplification phenotype observed in these lungs is supported by the literature. We were the first to report that gain of Tgf- $\beta 1$ expression in the neonatal lung led to a BPD like phenotype [40]. This was subsequently confirmed in neonatal mice [41]. In addition, the Tgf- $\beta$ signaling pathway has been shown to be upregulated in the lung of neonatal mice exposed to hyperoxia [42]. In summary, an intricate balance of Tgf- $\beta$ signaling during prenatal and early postnatal mouse lung development seems to be essential for proper lung development and alveologenesis.

In addition, we report that the transcriptomic changes occurring following hyperoxia versus normoxia exposure in the control lungs (especially for Fgf and Tgf- $\beta$ signaling as well as the epithelial markers) are suppressed in the $m i R-154$ overexpression lungs. We therefore propose that hyperoxia may be eliciting its effect on alveologenesis by suppressing the downregulation of miR-154 expression in AT2 cells. Thus, miR-154 down-regulation may be required to release a set of gene functions that are critical for the induction of alveolarization.

Interestingly, a link between Tgf- $\beta$ signalling and miR-154 was already described in the context of idiopathic pulmonary fibrosis (IPF). Milosevic and colleagues examined the involvement of $m i R-154$ in the fibrotic phenotype of IPF patients' lungs [43]. TGF- $\beta 1$ stimulation via its downstream effector SMAD3 in vitro elicited the upregulation of various members of a miRNA cluster, which is mapped on human chromosome $14 q 32$ and part of the imprinted DLK1-DIO3 domain. This cluster included miR-154. $m i R-154$ was shown to induce proliferation and migration in lung fibroblasts partly via the repression of p15 (CDKN2B) protein level, a cell cycle inhibitor, and induction of the WNT/ $\beta$-Catenin pathway.

The Dlk1-Dio3 locus which contains miR-154 was also described to be downstream of Histone deacetylase 3 (Hdac3). Hdac3 knockout mice display a reduction of AT1 cell spreading leading to sacculation defects [44]. Hdac3 represses both miR-17-92 as well as the miRNAs in the Dlk1-Dio3 locus, which are targeting Tgf- $\beta$ signaling. It was suggested that proper levels of Tgf- $\beta$ signaling are important for AT1 cell remodeling. Interestingly, if Hdac3 controls the expression of both miR-17-92 and $\operatorname{miR}-154$, this will lead to the combined activation and repression of Tgf- $\beta$ signaling. The final outcome in terms of Tgf- $\beta$ signaling will depend on the level of expression of these miRs as well as on the expression of the downstream miR targets in the cells of interest. This situation is not uncommon as we previously described that $m i R-142-3 p$ is capable of eliciting the inhibition of Wnt signaling via the targeting of the positive regulator $p 300$ and its activation via the targeting of the negative regulator Adenomatous polyposis coli (Apc) [45].

In conclusion, when considering the findings from the literature and taking into account our new results, we hypothesize that miR-154 could also function as an important factor for embryonic development, as its expression increases during the prenatal phases towards birth and then decreases after birth (in accordance with the findings from Williams et al. [19]). However, the role of miR-154 during fetal development is still unknown. In order to allow proper alveologenesis after birth, we also hypothesize that $m i R-154$ has to be decreased in expression, as both hyperoxic injury (and subsequent hyperoxia-mediated miR-154 activation) and postnatal miR-154 induction led to an impairment of alveolar formation also reflected in alveolar morphometric measurements (Figure 8A). Thus, the injurious effect of hyperoxic injury on alveolar formation appears to be at least partly mediated by induction of miR-154.

In our hypothetical model of action we hypothesize that under physiological conditions (Figure 8B) miR-154 must be downregulated postnatally in AT2 cells, unleashing the putative target Cav1, which in turn leads to a downregulation of Tgf- $\beta$ signaling by receptor internalization of Tgf- $\beta r 1$ [39]. However, in the context of hyperoxia injury (Figure $8 C$ ), a hyperoxia-induced up-regulation of miR-154 occurs, which inhibits Cav1-mediated Tgf- $\beta$ r1 receptor internalization, thereby maintaining Tgf- $\beta$ activity in AT2 cells leading to impairment of alveologenesis.

In conclusion, when miR-154 expression in AT2 is maintained postnatally, it targets Cav1 and thereby allows increased Tgf- $\beta 1$ signaling. Increased Tgf- $\beta 1$ signaling in AT2 cells in turn leads to their 
premature transdifferentiation towards an AT1 phenotype and this interrupts alveologenesis. Our work paves the way for the possible manipulation of the miR-154-Cav1-Tgf- $\beta$ signaling axis to attempt circumvention of the defective alveologenesis observed in lung diseases of human prematurity such as BPD, that are characterized by alveolar simplification.

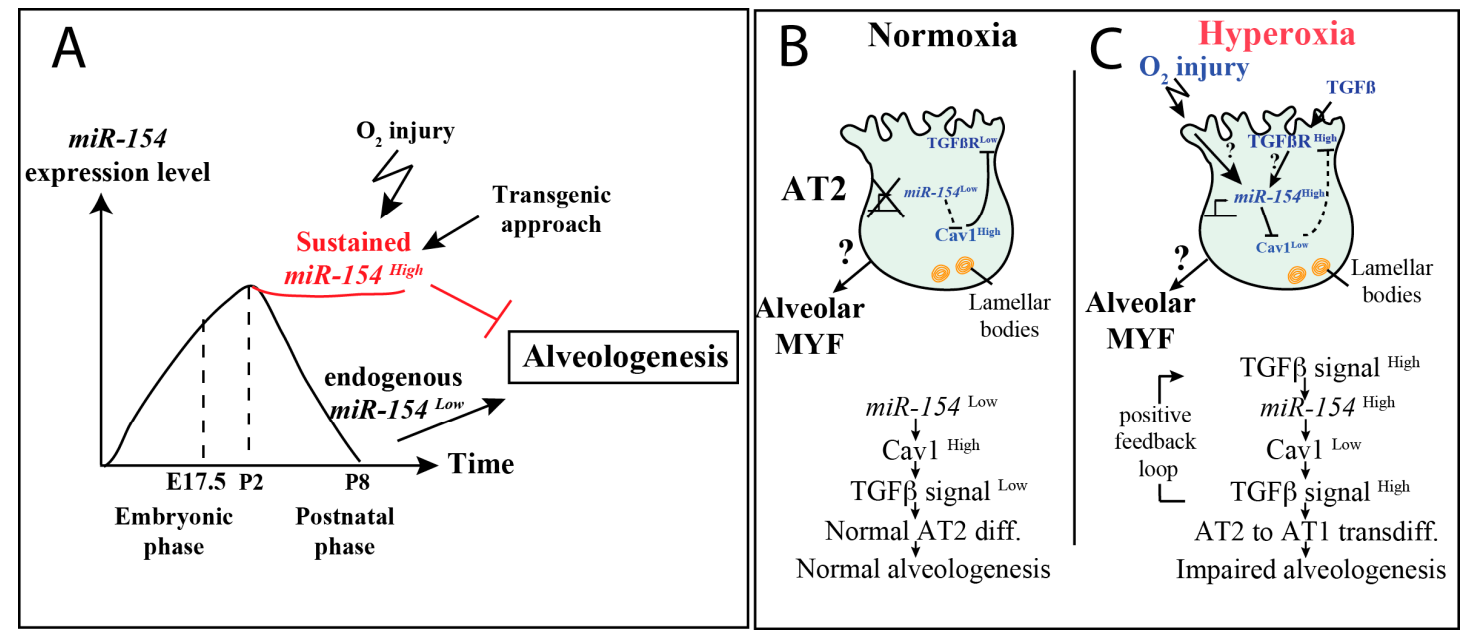

Figure 8. Hypothetical Model of Action describing miR-154 function in lung development. A. miR-154 expression level alterations during embryonic and postnatal phases. Postnatal miR-154 decrease allows proper alveologenesis, whereas hyperoxia-induced sustained miR-154 levels lead to the disturbance of alveologenesis. B. Under normoxic conditions postnatal miR-154 repression occurs to enable Cav1 to inhibit Tgf- $\beta$ signaling by Tgf- $\beta$ r1 internalization leading to proper alveologenesis in postnatal development. C. Hyperoxia leads to miR-154 induction and subsequent repression of Cav1-mediated Tgf- $\beta$ r1 internalization. Tgf- $\beta$ signaling is unleashed disturbing alveologenesis.

Supplementary Materials: The following are available online at http://www.mdpi.com/2073-4409/9/4/859/s1, Figure S1: Impact of hyperoxia versus normoxia exposure of wild type mice on lung morphometry. (A) Schematic of the normoxia or hyperoxia exposure followed by normoxia and analysis at P16. (B) H\&E staining of normoxia and hyperoxia lungs. (C) Morphometry measurement showing a significant increase in MLI. Scale bar in B: low magnification: $500 \mathrm{~m}$; high magnification: $200 \mathrm{~m}$.

Author Contributions: C.-M.C., G.C., D.W., S.B.: concept and design; C.-M.C., Z.A.R., J.K., J.S., V.Z., A.M., J.W. (Jochen Wilhelm), J.W. (Jin Wu), A.C.: acquisition of data; G.C., B.M.Y.: mouse construct; C.-M.C., G.C., G.B., D.W., S.B.: analysis and interpretation; C.-M.C., L.C., P.M., D.W., S.B.: drafting and editing of the manuscript. All authors have read and agreed to the published version of the manuscript.

Funding: C.-M.C. was funded by grants from the Excellence Cluster Cardio-Pulmonary System (ECCPS) and University Hospital Giessen and Marburg (UKGM). S.B. was supported by grants from the Deutsche Forschungsgemeinschaft (DFG; BE4443/14-1, BE4443/6-1, KFO309 P7 and SFB CRC1213-projects A02 and A04), the DZL and the First Affiliated Hospital of Wenzhou Medical University.

Acknowledgments: S.B. acknowledges the support of the CPI.

Conflicts of Interest: The authors declare no conflict of interest.

\section{References}

1. Kugler, M.C.; Loomis, C.A.; Zhao, Z.; Cushman, J.C.; Liu, L.; Munger, J.S. Sonic Hedgehog Signaling Regulates Myofibroblast Function during Alveolar Septum Formation in Murine Postnatal Lung. Am. J. Respir. Cell Mol. Biol. 2017, 57, 280-293. [CrossRef] [PubMed]

2. Bostrom, H.; Willetts, K.; Pekny, M.; Leveen, P.; Lindahl, P.; Hedstrand, H.; Pekna, M.; Hellstrom, M.; Gebre-Medhin, S.; Schalling, M.; et al. PDGF-A signaling is a critical event in lung alveolar myofibroblast development and alveogenesis. Cell 1996, 85, 863-873. [CrossRef] 
3. Popova, A.P.; Bentley, J.K.; Cui, T.X.; Richardson, M.N.; Linn, M.J.; Lei, J.; Chen, Q.; Goldsmith, A.M.; Pryhuber, G.S.; Hershenson, M.B. Reduced platelet-derived growth factor receptor expression is a primary feature of human bronchopulmonary dysplasia. Am. J. Physiol. Lung Cell Mol. Physiol. 2014, 307, L231-L239. [CrossRef] [PubMed]

4. Perl, A.K.; Gale, E. FGF signaling is required for myofibroblast differentiation during alveolar regeneration. Am. J. Physiol. Lung Cell Mol. Physiol. 2009, 297, L299-L308. [CrossRef] [PubMed]

5. Weinstein, M.; Xu, X.; Ohyama, K.; Deng, C.X. FGFR-3 and FGFR-4 function cooperatively to direct alveogenesis in the murine lung. Development 1998, 125, 3615-3623. [PubMed]

6. De Langhe, S.P.; Carraro, G.; Warburton, D.; Hajihosseini, M.K.; Bellusci, S. Levels of mesenchymal FGFR2 signaling modulate smooth muscle progenitor cell commitment in the lung. Dev. Biol. 2006, 299, 52-62. [CrossRef]

7. Baraldi, E.; Filippone, M. Chronic lung disease after premature birth. N Engl. J. Med. 2007, 357, $1946-1955$. [CrossRef]

8. Nardiello, C.; Morty, R.E. MicroRNA in late lung development and bronchopulmonary dysplasia: The need to demonstrate causality. Mol. Cell Pediatr. 2016, 3, 19. [CrossRef]

9. Chao, C.M.; El Agha, E.; Tiozzo, C.; Minoo, P.; Bellusci, S. A breath of fresh air on the mesenchyme: Impact of impaired mesenchymal development on the pathogenesis of bronchopulmonary dysplasia. Front. Med. (Lausanne) 2015, 2, 27. [CrossRef]

10. Northway, W.H., Jr.; Rosan, R.C.; Porter, D.Y. Pulmonary disease following respirator therapy of hyaline-membrane disease. Bronchopulmonary dysplasia. N Engl. J. Med. 1967, 276, 357-368. [CrossRef]

11. Voynow, J.A. “New” bronchopulmonary dysplasia and chronic lung disease. Paediatr. Respir. Rev. 2017, 24, 17-18. [CrossRef] [PubMed]

12. Owen, L.S.; Manley, B.J.; Davis, P.G.; Doyle, L.W. The evolution of modern respiratory care for preterm infants. Lancet 2017, 389, 1649-1659. [CrossRef]

13. Xing, Y.; Fu, J.; Yang, H.; Yao, L.; Qiao, L.; Du, Y.; Xue, X. MicroRNA expression profiles and target prediction in neonatal Wistar rat lungs during the development of bronchopulmonary dysplasia. Int. J. Mol. Med. 2015, 36, 1253-1263. [CrossRef] [PubMed]

14. Silva, D.M.; Nardiello, C.; Pozarska, A.; Morty, R.E. Recent advances in the mechanisms of lung alveolarization and the pathogenesis of bronchopulmonary dysplasia. Am. J. Physiol. Lung Cell Mol. Physiol. 2015, 309, L1239-L1272. [CrossRef] [PubMed]

15. Jonas, S.; Izaurralde, E. Towards a molecular understanding of microRNA-mediated gene silencing. Nat. Rev. Genet. 2015, 16, 421-433. [CrossRef]

16. Krol, J.; Loedige, I.; Filipowicz, W. The widespread regulation of microRNA biogenesis, function and decay. Nat. Rev. Genet. 2010, 11, 597-610. [CrossRef]

17. Sessa, R.; Hata, A. Role of microRNAs in lung development and pulmonary diseases. Pulm. Circ. 2013, 3, 315-328. [CrossRef]

18. Benetatos, L.; Hatzimichael, E.; Londin, E.; Vartholomatos, G.; Loher, P.; Rigoutsos, I.; Briasoulis, E. The microRNAs within the DLK1-DIO3 genomic region: Involvement in disease pathogenesis. Cell Mol. Life Sci. 2013, 70, 795-814. [CrossRef]

19. Williams, A.E.; Moschos, S.A.; Perry, M.M.; Barnes, P.J.; Lindsay, M.A. Maternally imprinted microRNAs are differentially expressed during mouse and human lung development. Dev. Dyn. 2007, 236, 572-580. [CrossRef]

20. Seitz, H.; Royo, H.; Bortolin, M.L.; Lin, S.P.; Ferguson-Smith, A.C.; Cavaille, J. A large imprinted microRNA gene cluster at the mouse Dlk1-Gtl2 domain. Genome Res. 2004, 14, 1741-1748. [CrossRef]

21. Dixon-McIver, A.; East, P.; Mein, C.A.; Cazier, J.B.; Molloy, G.; Chaplin, T.; Andrew Lister, T.; Young, B.D.; Debernardi, S. Distinctive patterns of microRNA expression associated with karyotype in acute myeloid leukaemia. PloS ONE 2008, 3, e2141. [CrossRef] [PubMed]

22. Lin, S.P.; Youngson, N.; Takada, S.; Seitz, H.; Reik, W.; Paulsen, M.; Cavaille, J.; Ferguson-Smith, A.C. Asymmetric regulation of imprinting on the maternal and paternal chromosomes at the Dlk1-Gtl2 imprinted cluster on mouse chromosome 12. Nat. Genet. 2003, 35, 97-102. [CrossRef] [PubMed] 
23. Kagami, M.; O’Sullivan, M.J.; Green, A.J.; Watabe, Y.; Arisaka, O.; Masawa, N.; Matsuoka, K.; Fukami, M.; Matsubara, K.; Kato, F.; et al. The IG-DMR and the MEG3-DMR at human chromosome 14q32.2: Hierarchical interaction and distinct functional properties as imprinting control centers. PloS Genet. 2010, 6, e1000992. [CrossRef] [PubMed]

24. Available online: http://www.mirbase.org/ (accessed on 1 December 2019).

25. Parsa, S.; Ramasamy, S.K.; De Langhe, S.; Gupte, V.V.; Haigh, J.J.; Medina, D.; Bellusci, S. Terminal end bud maintenance in mammary gland is dependent upon FGFR2b signaling. Dev. Biol. 2008, 317, 121-131. [CrossRef] [PubMed]

26. McGrath-Morrow, S.A.; Cho, C.; Soutiere, S.; Mitzner, W.; Tuder, R. The effect of neonatal hyperoxia on the lung of p21Waf1/Cip1/Sdi1-deficient mice. Am. J. Respir. Cell Mol. Biol. 2004, 30, 635-640. [CrossRef]

27. Woyda, K.; Koebrich, S.; Reiss, I.; Rudloff, S.; Pullamsetti, S.S.; Ruhlmann, A.; Weissmann, N.; Ghofrani, H.A.; Gunther, A.; Seeger, W.; et al. Inhibition of phosphodiesterase 4 enhances lung alveolarisation in neonatal mice exposed to hyperoxia. Eur. Respir. J. 2009, 33, 861-870. [CrossRef]

28. Seimetz, M.; Parajuli, N.; Pichl, A.; Veit, F.; Kwapiszewska, G.; Weisel, F.C.; Milger, K.; Egemnazarov, B.; Turowska, A.; Fuchs, B.; et al. Inducible NOS inhibition reverses tobacco-smoke-induced emphysema and pulmonary hypertension in mice. Cell 2011, 147, 293-305. [CrossRef]

29. Gentleman, R.C.; Carey, V.J.; Bates, D.M.; Bolstad, B.; Dettling, M.; Dudoit, S.; Ellis, B.; Gautier, L.; Ge, Y.; Gentry, J.; et al. Bioconductor: Open software development for computational biology and bioinformatics. Genome Biol. 2004, 5, R80. [CrossRef]

30. Smyth, G.K. Linear models and empirical bayes methods for assessing differential expression in microarray experiments. Stat. Appl. Genet. Mol. Biol. 2004, 3, 3. [CrossRef]

31. McQualter, J.L.; Yuen, K.; Williams, B.; Bertoncello, I. Evidence of an epithelial stem/progenitor cell hierarchy in the adult mouse lung. Proc. Natl. Acad. Sci. USA 2010, 107, 1414-1419. [CrossRef]

32. Sanders, Y.Y.; Cui, Z.; Le Saux, C.J.; Horowitz, J.C.; Rangarajan, S.; Kurundkar, A.; Antony, V.B.; Thannickal, V.J. SMAD-independent down-regulation of caveolin-1 by TGF-beta: Effects on proliferation and survival of myofibroblasts. PloS ONE 2015, 10, e0116995. [CrossRef] [PubMed]

33. Al Alam, D.; Danopoulos, S.; Schall, K.; Sala, F.G.; Almohazey, D.; Fernandez, G.E.; Georgia, S.; Frey, M.R.; Ford, H.R.; Grikscheit, T.; et al. Fibroblast growth factor 10 alters the balance between goblet and Paneth cells in the adult mouse small intestine. Am. J. Physiol. Gastrointest Liver Physiol. 2015, 308, G678-G690. [CrossRef] [PubMed]

34. Treutlein, B.; Brownfield, D.G.; Wu, A.R.; Neff, N.F.; Mantalas, G.L.; Espinoza, F.H.; Desai, T.J.; Krasnow, M.A.; Quake, S.R. Reconstructing lineage hierarchies of the distal lung epithelium using single-cell RNA-seq. Nature 2014, 509, 371-375. [CrossRef] [PubMed]

35. Kim, J.; Kang, Y.; Kojima, Y.; Lighthouse, J.K.; Hu, X.; Aldred, M.A.; McLean, D.L.; Park, H.; Comhair, S.A.; Greif, D.M.; et al. An endothelial apelin-FGF link mediated by miR-424 and miR-503 is disrupted in pulmonary arterial hypertension. Nat. Med. 2013, 19, 74-82. [CrossRef] [PubMed]

36. Al Alam, D.; El Agha, E.; Sakurai, R.; Kheirollahi, V.; Moiseenko, A.; Danopoulos, S.; Shrestha, A.; Schmoldt, C.; Quantius, J.; Herold, S.; et al. Evidence for the involvement of fibroblast growth factor 10 in lipofibroblast formation during embryonic lung development. Development 2015, 142, 4139-4150. [CrossRef]

37. de Maximy, A.A.; Nakatake, Y.; Moncada, S.; Itoh, N.; Thiery, J.P.; Bellusci, S. Cloning and expression pattern of a mouse homologue of drosophila sprouty in the mouse embryo. Mech. Dev. 1999, 81, 213-216. [CrossRef]

38. Jones, M.R.; Lingampally, A.; Dilai, S.; Shrestha, A.; Stripp, B.; Helmbacher, F.; Chen, C.; Chao, C.M.; Bellusci, S. Characterization of Tg(Etv4-GFP) and Etv5 (RFP) Reporter Lines in the Context of Fibroblast Growth Factor 10 Signaling During Mouse Embryonic Lung Development. Front. Genet. 2019, 10, 178. [CrossRef]

39. Hwangbo, C.; Tae, N.; Lee, S.; Kim, O.; Park, O.K.; Kim, J.; Kwon, S.H.; Lee, J.H. Syntenin regulates TGF-beta1-induced Smad activation and the epithelial-to-mesenchymal transition by inhibiting caveolin-mediated TGF-beta type I receptor internalization. Oncogene 2016, 35, 389-401. [CrossRef]

40. Gauldie, J.; Galt, T.; Bonniaud, P.; Robbins, C.; Kelly, M.; Warburton, D. Transfer of the active form of transforming growth factor-beta 1 gene to newborn rat lung induces changes consistent with bronchopulmonary dysplasia. Am. J. Pathol. 2003, 163, 2575-2584. [CrossRef] 
41. Vicencio, A.G.; Lee, C.G.; Cho, S.J.; Eickelberg, O.; Chuu, Y.; Haddad, G.G.; Elias, J.A. Conditional overexpression of bioactive transforming growth factor-beta1 in neonatal mouse lung: A new model for bronchopulmonary dysplasia? Am. J. Respir. Cell Mol. Biol. 2004, 31, 650-656. [CrossRef]

42. Alejandre-Alcazar, M.A.; Kwapiszewska, G.; Reiss, I.; Amarie, O.V.; Marsh, L.M.; Sevilla-Perez, J.; Wygrecka, M.; Eul, B.; Kobrich, S.; Hesse, M.; et al. Hyperoxia modulates TGF-beta/BMP signaling in a mouse model of bronchopulmonary dysplasia. Am. J. Physiol. Lung Cell Mol. Physiol. 2007, 292, L537-L549. [CrossRef] [PubMed]

43. Milosevic, J.; Pandit, K.; Magister, M.; Rabinovich, E.; Ellwanger, D.C.; Yu, G.; Vuga, L.J.; Weksler, B.; Benos, P.V.; Gibson, K.F.; et al. Profibrotic role of miR-154 in pulmonary fibrosis. Am. J. Respir. Cell Mol. Biol. 2012, 47, 879-887. [CrossRef] [PubMed]

44. Wang, Y.; Frank, D.B.; Morley, M.P.; Zhou, S.; Wang, X.; Lu, M.M.; Lazar, M.A.; Morrisey, E.E. HDAC3-Dependent Epigenetic Pathway Controls Lung Alveolar Epithelial Cell Remodeling and Spreading via miR-17-92 and TGF-beta Signaling Regulation. Dev. Cell 2016, 36, 303-315. [CrossRef] [PubMed]

45. Shrestha, A.; Carraro, G.; El Agha, E.; Mukhametshina, R.; Chao, C.M.; Rizvanov, A.; Barreto, G.; Bellusci, S. Generation and Validation of miR-142 Knock Out Mice. PloS ONE 2015, 10, e0136913. [CrossRef]

(C) 2020 by the authors. Licensee MDPI, Basel, Switzerland. This article is an open access article distributed under the terms and conditions of the Creative Commons Attribution (CC BY) license (http://creativecommons.org/licenses/by/4.0/). 